\title{
Observations of the April 2002 geomagnetic storm by the global network of incoherent scatter radars
}

\author{
L. P. Goncharenko ${ }^{1}$, J. E. Salah ${ }^{1}$, A. van Eyken ${ }^{2}$, V. Howells ${ }^{3}$, J. P. Thayer ${ }^{4}$, V. I. Taran $^{5}$, B. Shpynev ${ }^{6}$, Q. Zhou ${ }^{7}$, and \\ J. Chau ${ }^{8}$ \\ ${ }^{1}$ Massachusetts Institute of Technology, Haystack Observatory, Westford, MA, USA \\ ${ }^{2}$ EISCAT Scientific Association, PO Box 432, Longyearbyen, Norway \\ ${ }^{3}$ Space Physics Division, Rutherford Appleton Laboratory, Didcot, Oxon, UK \\ ${ }^{4}$ University of Colorado, Aerospace Engineering Sciences Boulder, CO, USA \\ ${ }^{5}$ Institute for Ionosphere, Kharkov, Ukraine \\ ${ }^{6}$ Institute for Solar-Terrestrial Physics, Irkutsk, Russia \\ ${ }^{7}$ Electrical and Computer Eng. Dept., Miami University, Oxford, OH, USA \\ ${ }^{8}$ Radio Observatorio de Jicamarca, Instituto Geofisico del Peru, Lima 33, Peru
}

Received: 8 October 2003 - Revised: 21 October 2004 - Accepted: 27 October 2004 - Published: 31 January 2005

Part of Special Issue "Eleventh International EISCAT Workshop"

\begin{abstract}
This paper describes the ionospheric response to a geomagnetic storm beginning on 17 April 2002. We present the measurements of ionospheric parameters in the F-region obtained by the network of eight incoherent scatter radars. The main effects of this storm include a deep decrease in the electron density observed at high and middle latitudes in the pre-noon sector, and a minor enhancement in the density observed in the daytime sector at middle latitudes. Extreme plasma heating $(>1000-3000 \mathrm{~K})$ is observed at high latitudes, subsiding to $200-300 \mathrm{~K}$ at subauroral latitudes. The western hemisphere radar chain observed the prompt penetration of the electric field from auroral to equatorial latitudes, as well as the daytime enhancement of plasma drift parallel to the magnetic field line, which is related to the enhancement in the equatorward winds. We suggest that in the first several hours after the storm onset, a negative phase above Millstone Hill (pre-noon sector) results from counteracting processes - penetration electric field, meridional wind, and electrodynamic heating, with electrodynamic heating being the dominant mechanism. At the lower latitude in the prenoon sector (Arecibo and Jicamarca), the penetration electric field becomes more important, leading to a negative storm phase over Arecibo. In contrast, in the afternoon sector at mid-latitudes (Kharkov, Irkutsk), effects of penetration electric field and meridional wind do not counteract, but add up, leading to a small $(\sim 15 \%)$, positive storm phase over these locations. As the storm develops, Millstone Hill and Irkutsk mid-latitude radars observe further depletion of electron density due to the changes in the neutral composition.
\end{abstract}

Correspondence to: L. P. Goncharenko

(lpg@ haystack.mit.edu)
Key words. Ionosphere (Auroral ionosphere; Mid-latitude ionosphere; Equatorial ionosphere) - Magnetosphereic physics (Storm and substorms)

\section{Introduction}

The investigation of the effects of geomagnetic storms on the Earth's upper atmosphere is an essential component of the study of the impact that solar disturbances exert on space weather. Our current understanding of ionospheric storms based on ground-based observations was most recently reviewed by Buonsanto (1999). A key goal of various studies discussed in that review has been the assessment of the propagation of storm effects in latitude and longitude, such as the penetration of electric fields from high to low latitudes, the enhancements in the equatorward neutral winds, and the dusk enhancements in electron density at mid-latitudes (e.g. Fejer and Scherliess, 1998; Hocke and Schlegel, 1996; Foster, 1993). Global circulation models provide an important prediction of storm effects (e.g. Fuller-Rowell et al., 1997; Lu et al., 1998), and direct measurements through networks of instrumentation, such as GPS receivers, ionosondes and incoherent scatter radars, serve to identify the global effects (e.g. Pi et al., 1997; Field and Rishbeth, 1997; Buonsanto et al., 1999a,b). Models and observations complement each other and both are essential to the improved understanding of storm phenomena and their effects.

Global coverage of storm effects through observations is particularly important since the effects are generally a result of interactions between thermodynamics and composition, both of which are global in their extent and are difficult 


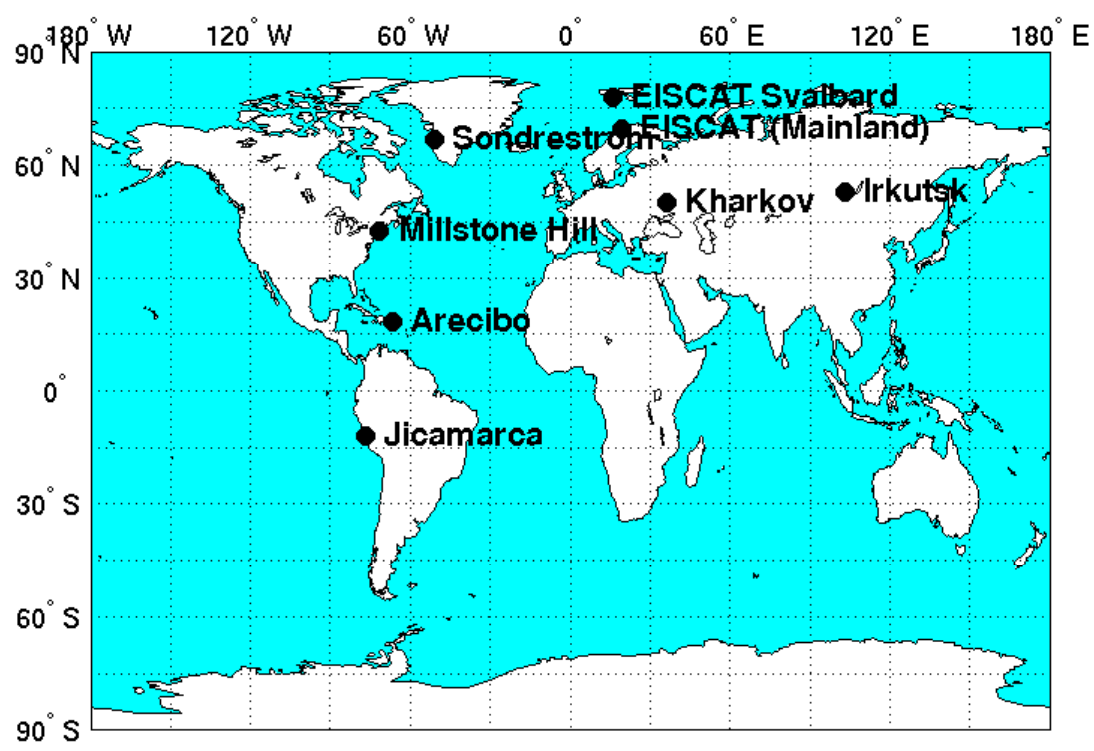

Fig. 1. Locations of incoherent scatter radars.

Table 1. Radar information.

\begin{tabular}{lccrccc}
\hline Radar & Invar. lat. & Geod. lat. & Geod. lon. & L-shell & $\begin{array}{c}\text { Time of sunrise } \\
\text { at 350 km, UT }\end{array}$ & $\begin{array}{c}\text { Time of sunset } \\
\text { at 350 km, UT }\end{array}$ \\
\hline EISCAT Svalbard & $74.87^{\circ}$ & $78.1^{\circ} \mathrm{N}$ & $16.0^{\circ} \mathrm{E}$ & $\sim 20$ & - & - \\
Sondrestrom & $73.17^{\circ}$ & $67.0^{\circ} \mathrm{N}$ & $309.1^{\circ} \mathrm{E}$ & $\sim 14$ & - & - \\
EISCAT Mainland & $66.40^{\circ}$ & $69.6^{\circ} \mathrm{N}$ & $19.2^{\circ} \mathrm{E}$ & $\sim 6.5$ & - & - \\
Millstone Hill & $53.40^{\circ}$ & $42.6^{\circ} \mathrm{N}$ & $288.5^{\circ} \mathrm{E}$ & 2.8 & 08.34 & 01.19 \\
Irkutsk & $45.89^{\circ}$ & $52.9^{\circ} \mathrm{N}$ & $103.1^{\circ} \mathrm{E}$ & 2.1 & 19.67 & 14.55 \\
Kharkov & $45.75^{\circ}$ & $50.0^{\circ} \mathrm{N}$ & $36.2^{\circ} \mathrm{E}$ & 2.1 & 00.78 & 18.41 \\
Arecibo & $32.18^{\circ}$ & $18.3^{\circ} \mathrm{N}$ & $293.3^{\circ} \mathrm{E}$ & 1.4 & 08.83 & 00.01 \\
Jicamarca & $13.90^{\circ}$ & $12.0^{\circ} \mathrm{S}$ & $283.1^{\circ} \mathrm{E}$ & 1.1 & 10.00 & 00.26 \\
\hline
\end{tabular}

to study at a particular location in isolation. There is also close coupling between the plasma and neutral components of the upper atmosphere at all altitudes which necessitates observations of both species, if possible. The collection and analysis of such data has therefore been a primary goal of the joint activities amongst the incoherent scatter facilities through programs such as CEDAR - Coupling, Energetics, Dynamics of Atmospheric Regions. Accordingly, coordinated campaigns have been organized by the community to activate the necessary instrumentation at the onset of major geomagnetic storms, in order to collect the necessary data. In particular, this paper presents the observations made by the global network of incoherent scatter radars of a storm event that occurred starting on 17 April 2002. To the best of our knowledge, this is the first occasion when eight incoherent scatter radars have made simultaneous measurements based on a storm alert condition.

The locations of the incoherent scatter radars that participated in the April 2002 campaign are shown in Fig. 1, and the radar coordinates, both geographic and geomagnetic, are given in Table 1. Three radars, the EISCAT Svalbard Radar - ESR $\left(78^{\circ} \mathrm{N}, 16^{\circ} \mathrm{E}\right)$, the EISCAT mainland radar $\left(70^{\circ} \mathrm{N}\right.$, $\left.19^{\circ} \mathrm{E}\right)$ and Sondrestrom $\left(67^{\circ} \mathrm{N}, 51^{\circ} \mathrm{W}\right)$, are well situated to observe the high-latitude effects. Three radars, Millstone Hill $\left(43^{\circ} \mathrm{N}, 71^{\circ} \mathrm{W}\right)$, Kharkov $\left(50^{\circ} \mathrm{N}, 36^{\circ} \mathrm{E}\right)$ and Irkutsk $\left(53^{\circ} \mathrm{N}, 103^{\circ} \mathrm{E}\right)$, are located along a mid-latitude longitude circle suitable for examining longitudinal effects, although it is noted that their geomagnetic latitudes differ substantially, with Millstone Hill being at $53^{\circ}$ invariant latitude and Kharkov and Irkutsk being at $46^{\circ}$ invariant latitude. Finally, four radars, Sondrestrom, Millstone Hill, Arecibo $\left(18^{\circ} \mathrm{N}\right.$, $\left.67^{\circ} \mathrm{W}\right)$ and Jicamarca $\left(12^{\circ} \mathrm{S}, 77^{\circ} \mathrm{W}\right)$ are well situated to determine the variation of the storm effects as a function of latitude along the North American longitude of $\sim 70^{\circ} \mathrm{W}$. Table 1 also shows the time of local sunrise and sunset at ionospheric altitudes $(350 \mathrm{~km})$ for each radar, and it is noted that ionospheric altitudes at the high-latitude locations during the April 2002 campaign are sunlit at all times.

The network of incoherent scatter radars were on standby mode starting in early April in expectation of a potential 

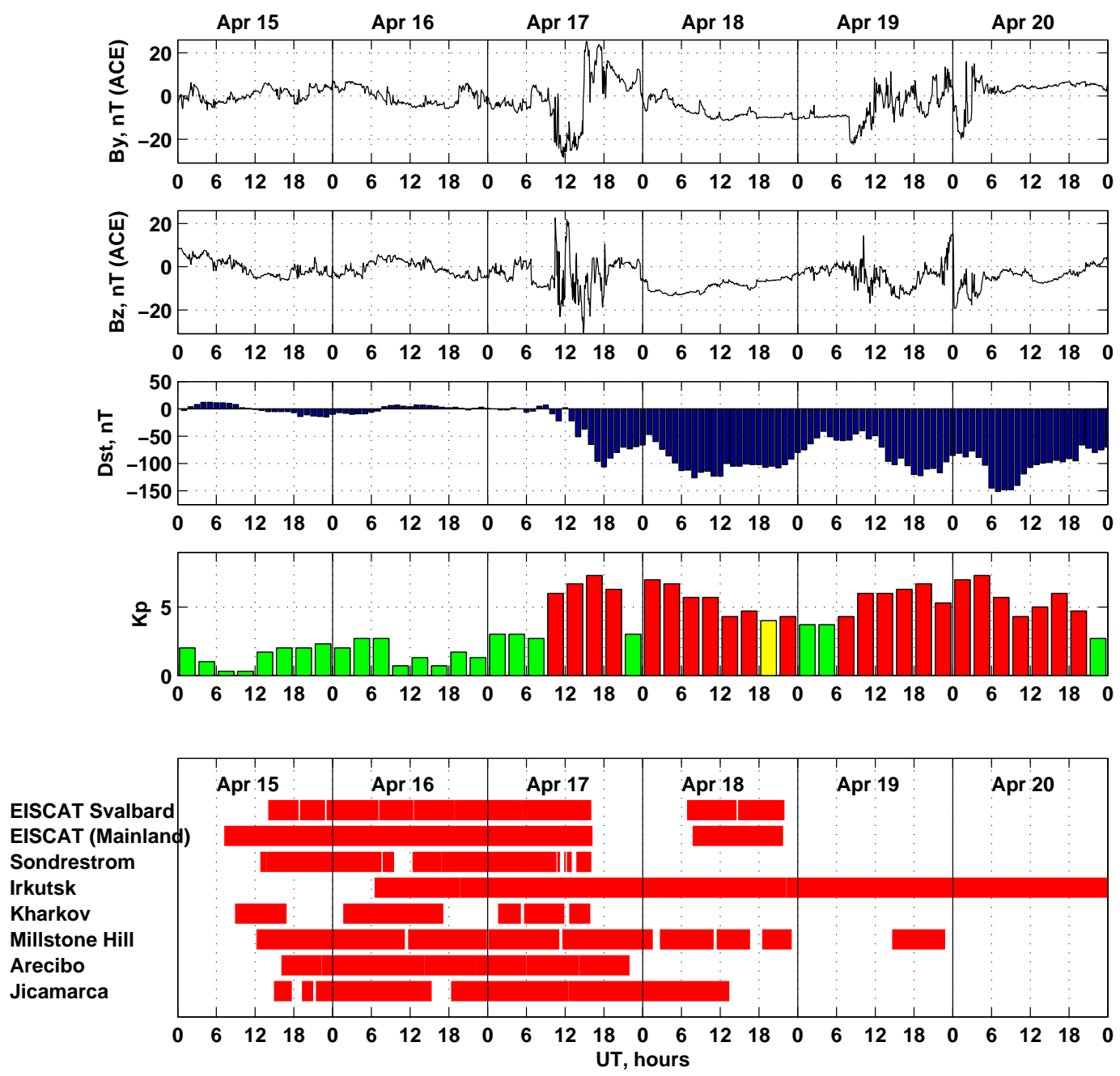

Fig. 2. The IMF $B_{y}$ and $B_{z}$ components (as measured by ACE satellite), the $D_{s t}$ index, $K_{p}$ index and data coverage of incoherent scatter radars during April 2002 campaign.

storm event. Careful monitoring of solar conditions through satellites and through information disseminated by the Solar Environment Center at the National Oceanic and Atmospheric Agency (NOAA) led to a global alert to be issued for the initiation of measurements on 15 April. The trigger for the alert was the eruption of an M-class solar flare (Active Region 9906) at 05:00 UT on 15 April observed by the SOHO satellite, with a halo CME reported by other space observations. The activation of ground-based measurements on 15 April provided some relatively quiet conditions for comparison of the ionosphere before the arrival at Earth of the storm effects on 17 April. At the time of the storm onset on 17 April, a second flare erupted on the Sun at 08:45 UT, and its effects arrived two days later at Earth. A third event, an X-ray flare, erupted at 04:12 UT on 21 April. The incoherent scatter observations continued at all radars through 17 April, thus covering the effects of the first flare, and some of the radars operated for an extended period beyond the initial interval, as will be discussed below. In this paper, we focus on the analysis of the incoherent scatter radar data, namely electron density, electron and ion temperature, and plasma drifts in the ionospheric F-region, above $200 \mathrm{~km}$. Section 2.1 describes the prevailing geomagnetic conditions for the April 2002 storm events and the data coverage by each of the eight radars. This is then followed by a presentation of the ionospheric observations at high latitudes (Sect. 2.2), at middle latitudes, as a function of longitude (Sect. 2.3), and along the $70^{\circ} \mathrm{W}$ meridian, as a function of latitude (Sect. 2.4). Section 3 presents a summary of the conclusions derived from the study.

\section{Observations}

\subsection{Solar-geophysical conditions and data coverage}

Figure 2 presents a summary of key parameters representing the conditions before and during the April 2002 storms. The two top panels show the $B_{y}$ and $B_{z}$ components of IMF data as observed by the ACE satellite. On 17 April, the IMF 

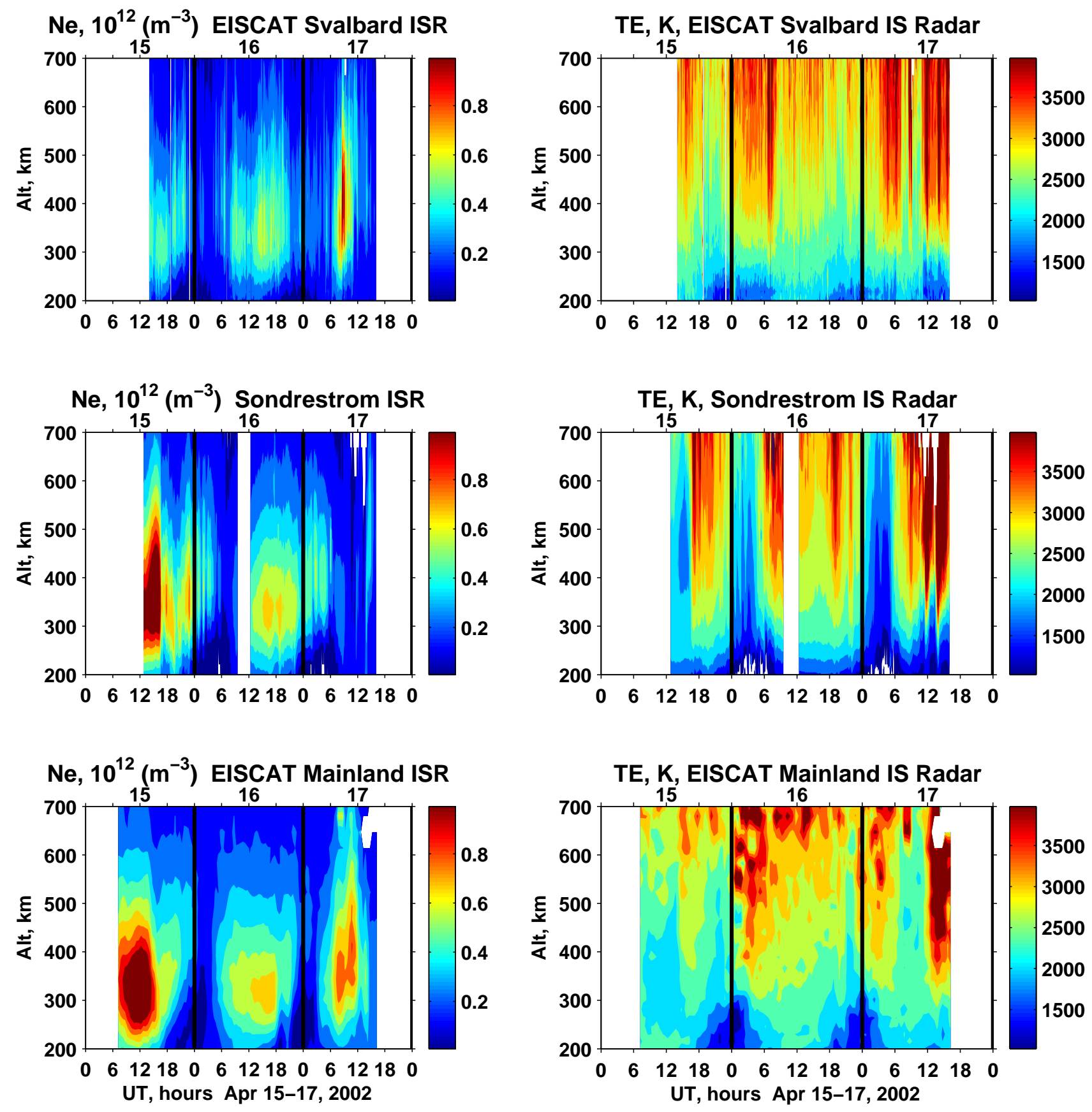

Fig. 3. Variations in the electron density (left panel) and electron temperature (right panel) on 15-17 April 2002 at high-latitude locations EISCAT Svalbard (top), Sondrestrom (middle), and EISCAT mainland (bottom).

$B_{z}$ component turns southward after 06:00 UT, and changes direction between southward and northward several times throughout the day. The arrival of the magnetic cloud at the ACE location is demonstrated as a sharp southward turning in the $B_{z}$ component at about 11:00 UT. The geomagnetic $D_{s t}$ index reached the first minimum value of $-106 \mathrm{nT}$ at 18:00 UT on 17 April, marking the main phase of the storm. After the initial recovery, $D_{s t}$ decreased again to $-126 \mathrm{nT}$ at 08:00 UT on 18 April with subsequent minima on 19 April and 20 April. The $K_{p}$ index reached $7+$ during
15:00-18:00 UT on 17 April, and remained at disturbed levels for the most part through 20 April, with other maxima reaching 7 at 00:00-03:00 UT on 18 April and 7+ at 03:0006:00 on 20 April.

The coordinated data set from the incoherent scatter radar network was collected during the prime observing interval centered on 15-17 April 2002, with some radars extending their observations to 18-20 April. The exact observation times at each radar are shown in the bottom panel of Fig. 2. 


\subsection{High latitudes}

Figures 3 and 4 show key ionospheric parameters measured in the high-latitude F-region: electron density (Fig. 3, left panel), electron temperature (Fig. 3, right panel) and ion temperature (Fig. 4). Only high elevation angle data were selected for Figs. 3 and 4 to represent ionospheric behavior above each site, leading to lower temporal resolution of EISCAT mainland radar data. Both figures contain data for 3 days, 15-17 April, with 15-16 April serving as quiet reference days. During the quiet time, electron density changes from the maximum value of $\sim 1.5 \times 10^{12} \mathrm{~m}^{-3}$ in the daytime to $\sim 0.1 \ldots 0.3 \times 10^{12} \mathrm{~m}^{-3}$ at local midnight, as can be seen in the left panel of Fig. 3. Electron temperature (Fig. 3, right panel) ranges from $2500 \ldots 3500 \mathrm{~K}$ in the daytime to $1500 \ldots .2000 \mathrm{~K}$ at night, with smaller day-to-night variations observed at the EISCAT Svalbard radar. During the quiet time, all ionospheric parameters experience large variations in magnitude during the night hours, reflecting the complexity of the high-latitude region and its sensitivity to processes in the magnetosphere and solar wind. Daytime observations are typical for these locations and season, with EISCAT Svalbard and Sondrestrom data reflecting measurements mostly within the relatively stable auroral oval, while nighttime data represent locations poleward of the auroral oval. To facilitate comparisons, Figs. 5 and 6 present variations in electron density and ion temperature at $350 \mathrm{~km}$, averaged at 15 -min intervals, for the three radars for each day of the campaign.

Distinctive enhancement in Ne occurred on 17 April at Svalbard between 07:00 and 11:00 UT at 250-600 km, which could be caused by the dayside cusp activity. The polar cusp regions are usually extended within $\sim 5^{\circ}$ of latitude around $\sim 77^{\circ}$ (geomagnetic), and solar wind particles can enter the magnetosphere within several hours around local noon time (Hunsucker and Hargreaves, 2003). At ionospheric heights, it results in the highly structured enhancement of electron density and sharp variations in electron and ion temperature, as observed over Svalbard. In contrast, similar enhancement in electron density observed by the EISCAT mainland radar, is accompanied not by an increase, but by a sharp drop in electron temperature (see Fig. 3), and can result from plasma convection into the radar field-of-view.

After the storm onset at $\sim 11: 00$ UT on 17 April, the F-region electron density decreases sharply at all high latitude locations. Within less than an hour, the electron density is depleted by a factor of 2-3 over Svalbard and EISCAT mainland. At Sondrestrom, which is located in the pre-noon sector, electron density decreased by a factor of 4-6 compared to the previous day. At the EISCAT radars, electron temperature is increased by $400 \ldots .2000 \mathrm{~K}$ at the higher F-region altitudes, while ion temperature enhanced by $200 \ldots .500 \mathrm{~K}$, with higher temperatures observed over the EISCAT mainland. Much higher increases in plasma temperatures are observed by Sondrestrom, where ion temperature is enhanced by $1000 \ldots 3000 \mathrm{~K}$, and very high Joule heating rates were recorded (Thayer et al., 2002). Relatively smooth variations in plasma parameters are accompanied
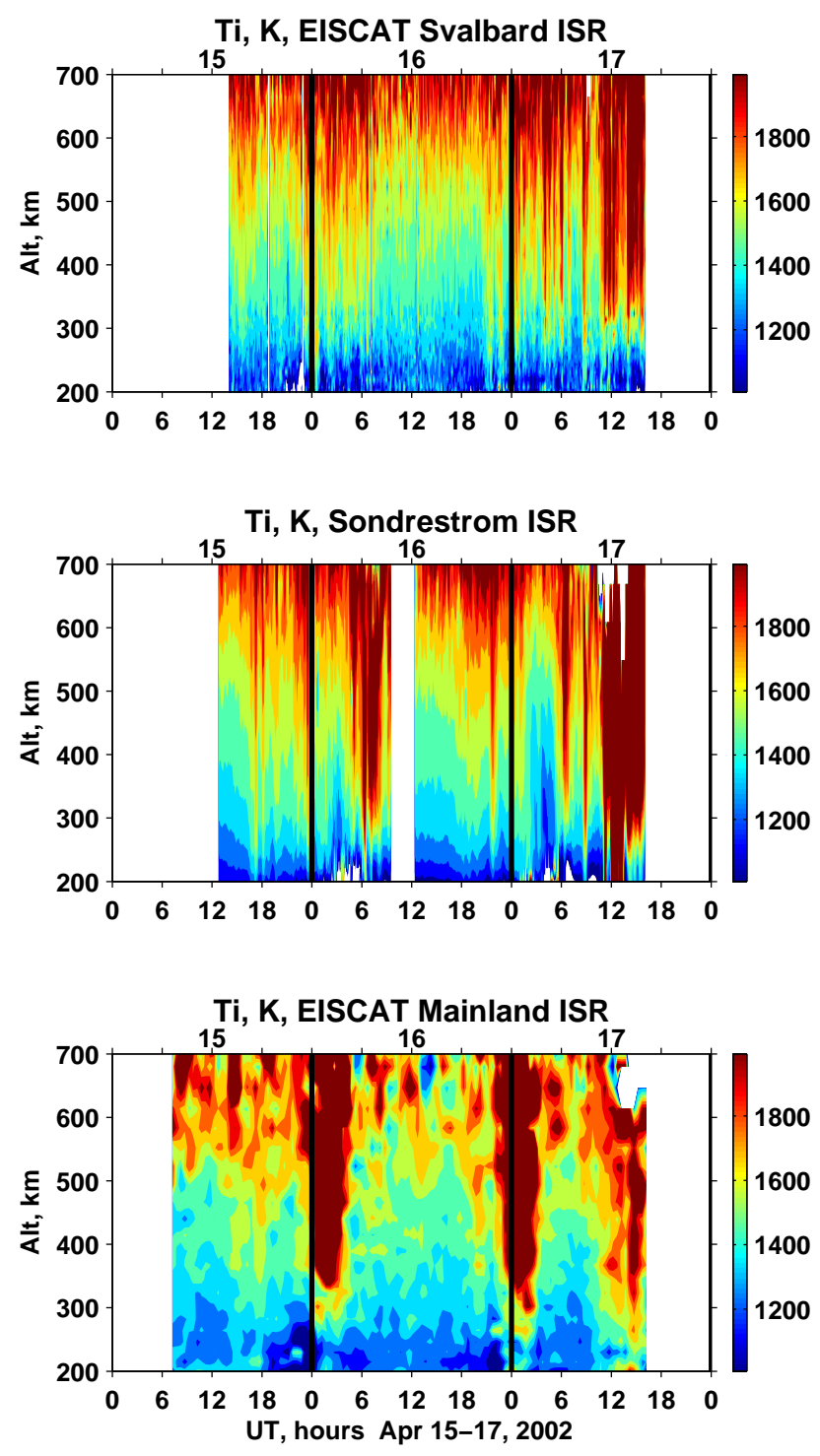

Fig. 4. Variations in the ion temperature on 15-17 April 2002 at high-latitude locations EISCAT Svalbard (top), Sondrestrom (middle) and EISCAT mainland (bottom).

by highly-structured, short-lived increases in ionization and temperatures observed close to $\sim 12: 00$ UT and 14:00 UT at Svalbard, and almost simultaneously $(\sim 11: 45$ UT and 14:00 UT) at Sondrestrom.

It is important to note that plasma temperatures derived from the radar measurements are very sensitive to the assumed ion composition (i.e. Moorcroft and Schlegel, 1988; Haggstrom and Collis, 1990; Jenkins et al., 1997), and we can expect that the increase in plasma temperatures is underestimated in this data, as well as in other radar data in this study. Fitting of incoherent scatter spectra for ionospheric parameters is generally difficult when the ion composition is unknown, and one approach to obtain more accurate plasma temperatures from incoherent scatter radar data would be to use ion composition from a model, as was done by Jenkins 

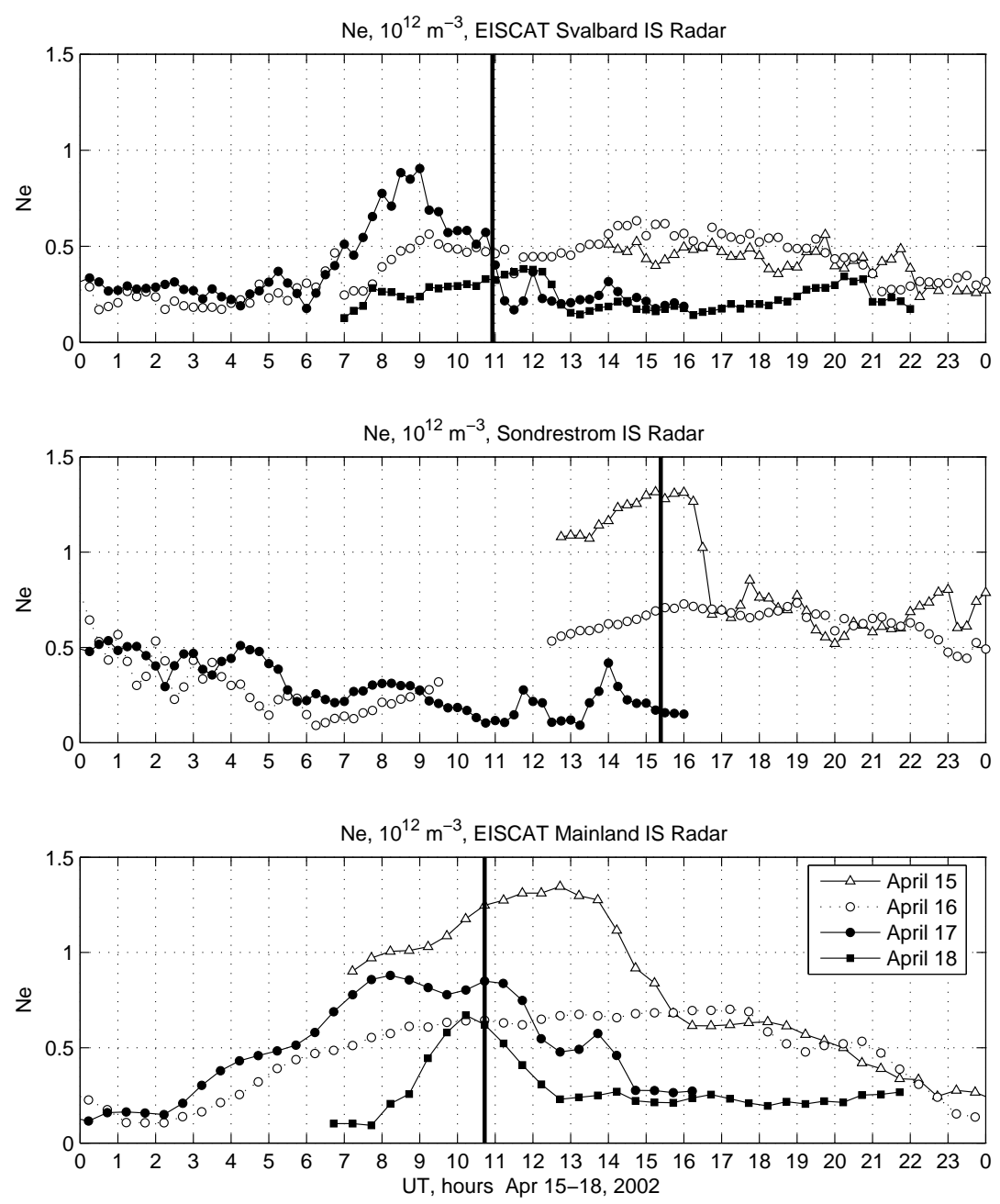

Fig. 5. Electron density at $350 \mathrm{~km}$ measured by Svalbard ISR (top), Sondrestrom ISR (middle), and EISCAT Mainland ISR (bottom). Vertical lines show local noon for each location.

et al. (1997) and Pavlov et al. (1999). Such corrections need to be performed for more detailed studies.

Large depletions in electron density as a result of a geomagnetic storm are very common at high latitudes (i.e. Prölss, 1995; Mikhailov and Schlegel, 1998; Liu et al., 2000). Several mechanisms could be responsible for these depletions. The strong electric field plays a crucial role, especially at the beginning of the storm. It can quickly transport plasma from areas of lower density and enhance the contribution of non-local processes. Besides plasma transport, the electric field can further deplete high-latitude ionization due to the large increase in the linear loss coefficient for O+ ions (Schunk et al., 1975; Prölss, 1995). Enhanced Joule heating can also result in ion outflow and a subsequent decrease in the density, as was shown by Idenden et al. (1997). Finally, as the storm develops, a decrease in the $\mathrm{O} / \mathrm{N}_{2}$ ratio due to composition changes contributes to the further depletion in ionization (Mikhailov and Schlegel, 1998). Assuming that the increase in ion temperature indicates the level of Joule heating and, therefore, the strength of the electric field, large Ti enhancement over Sondrestrom demonstrates that the electric field was very strong, as we will see later in Sect. 2.4.2, and produced severe depletion in the F-region. However, much smaller ion heating over EISCAT locations is a primary cause of a moderate (factor of $\sim 2$ ) decrease in electron density over these radars.

\subsection{Subauroral and middle latitudes}

Figure 7 shows time variations in electron density (left panel) and electron temperature (right panel) at three mid-latitude locations: Millstone Hill (top), Irkutsk (middle) and Kharkov (bottom), while Fig. 8 depicts variations in ion temperature at the same locations. Only daytime data are available for the Kharkov radar. At Irkutsk, an instrumentation problem resulted in a data gap in plasma temperatures on 17 April, while plasma density measurements were not affected.

Quiet-time electron density behavior for this period is typical for the mid-latitude ionosphere, with the electron density reaching maximum of $1.5 \ldots .2 \times 10^{12} \mathrm{~m}^{-3}$, and a secondary maximum forming in the local evening (see Fig. 7, 

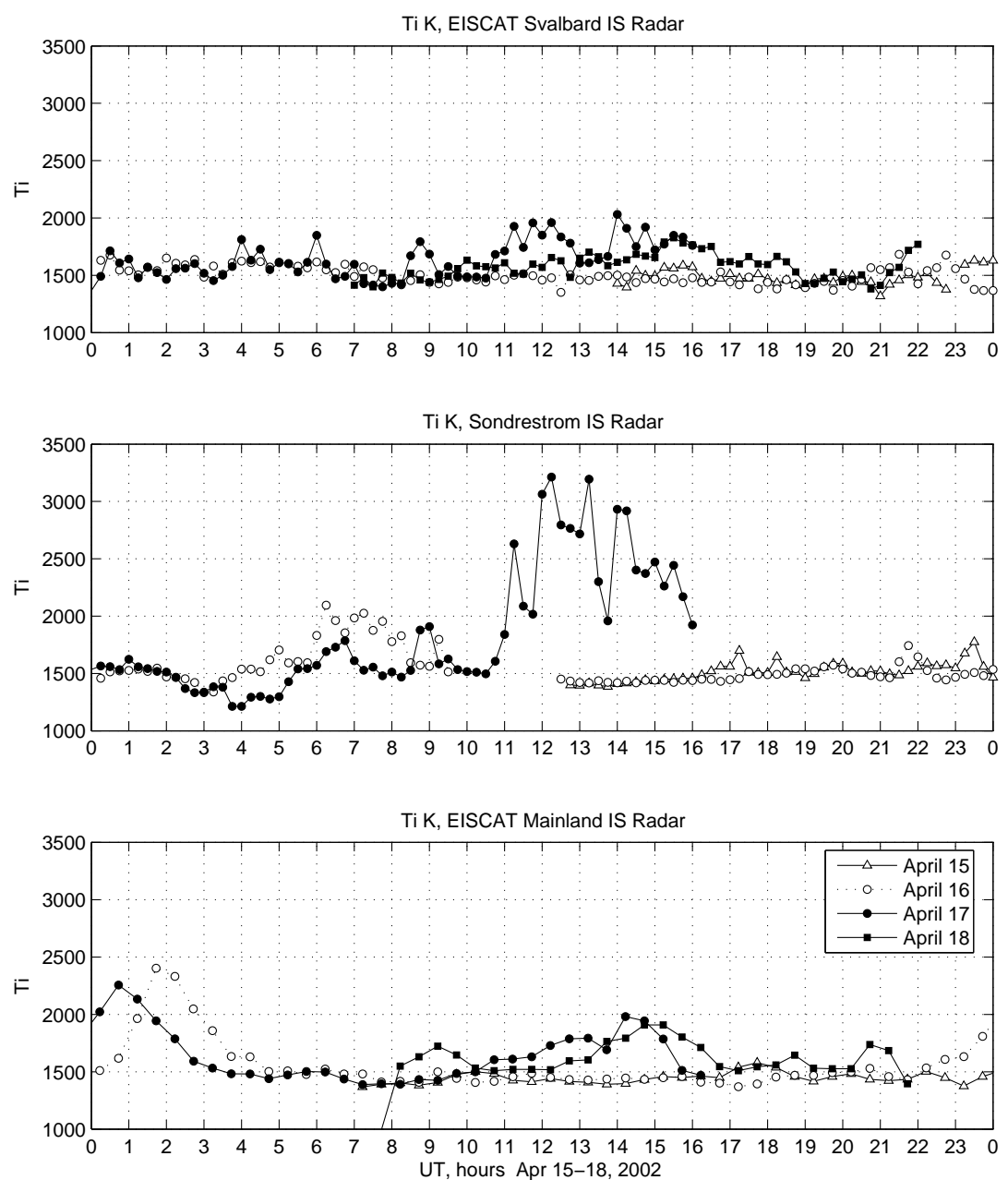

Fig. 6. Ion temperature at $350 \mathrm{~km}$ measured by Svalbard ISR (top), Sondrestrom ISR (middle), and EISCAT Mainland ISR (bottom).

22:00-24:00 UT on 15 April for Millstone Hill and 11:0013:00 UT on 16 April for Irkutsk). This maximum is formed due to diurnal changes in thermospheric circulation, namely equatorward turning of the meridional wind in the evening hours (Kohl and King, 1967; Rishbeth, 1967; Buonsanto and Witasse, 1999). As the equatorward wind moves plasma upwards along the magnetic field line, the recombination is slower. This effect is often enhanced by increased plasmaspheric downward flow due to plasma cooling in the evening hours. It is interesting to note that due to high electron density related to high solar activity, the electron cooling rates are enhanced (e.g. Roble, 1975), leading to the daytime "biteout" in the electron temperature profile at altitudes around the F-region maximum (see Fig. 7, right panel, 17:00-19:00 UT on 15 April for Millstone Hill and 8:00-11:00 UT on 1516 April for Kharkov). This effect is most pronounced over Arecibo, as will be shown in Fig. 10, where the electron density reaches $2.2 \times 10^{12} \mathrm{~m}^{-3}$, but is clearly observed at other mid-latitude ISRs, and for a short time, appears even at high latitudes.

Figure 9 presents variations in electron density at $350 \mathrm{~km}$ measured by Millstone Hill (top), Irkutsk (middle), and
Kharkov (bottom) for all available days during this campaign. At Millstone Hill, the effect of the storm is a major depletion of electron density beginning right after the storm onset on 17 April (i.e. local morning) and observed both in the daytime and at night. It is generally believed that the major cause of such depletions (i.e. negative storm effect) is a change in the neutral composition because of the heating of the thermosphere. It should be noted that as the heated gas expands from higher to lower latitudes, the thermospheric temperature remains enhanced at locations with a depleted $\mathrm{O} / \mathrm{N}_{2}$ ratio, and this temperature increase leads to higher recombination and lower electron density, as discussed by Mikhailov et al. (1995) and Mikhailov and Foster (1997). Extremely low densities $\left(<0.2 \times 10^{12} \mathrm{~m}^{-3}\right)$ were observed on 18 April between $\sim 03: 00$ and 09:00 UT (i.e. local night). They correspond to the electron density trough expanding to the Millstone Hill latitude, which is a common occurrence for Millstone Hill during geomagnetic storms. The electron temperature on the disturbed days increased by $200 \ldots .500 \mathrm{~K}$ with respect to the nearest quiet day, 16 April, likely due to the low electron density which reduces the electron cooling rate. 

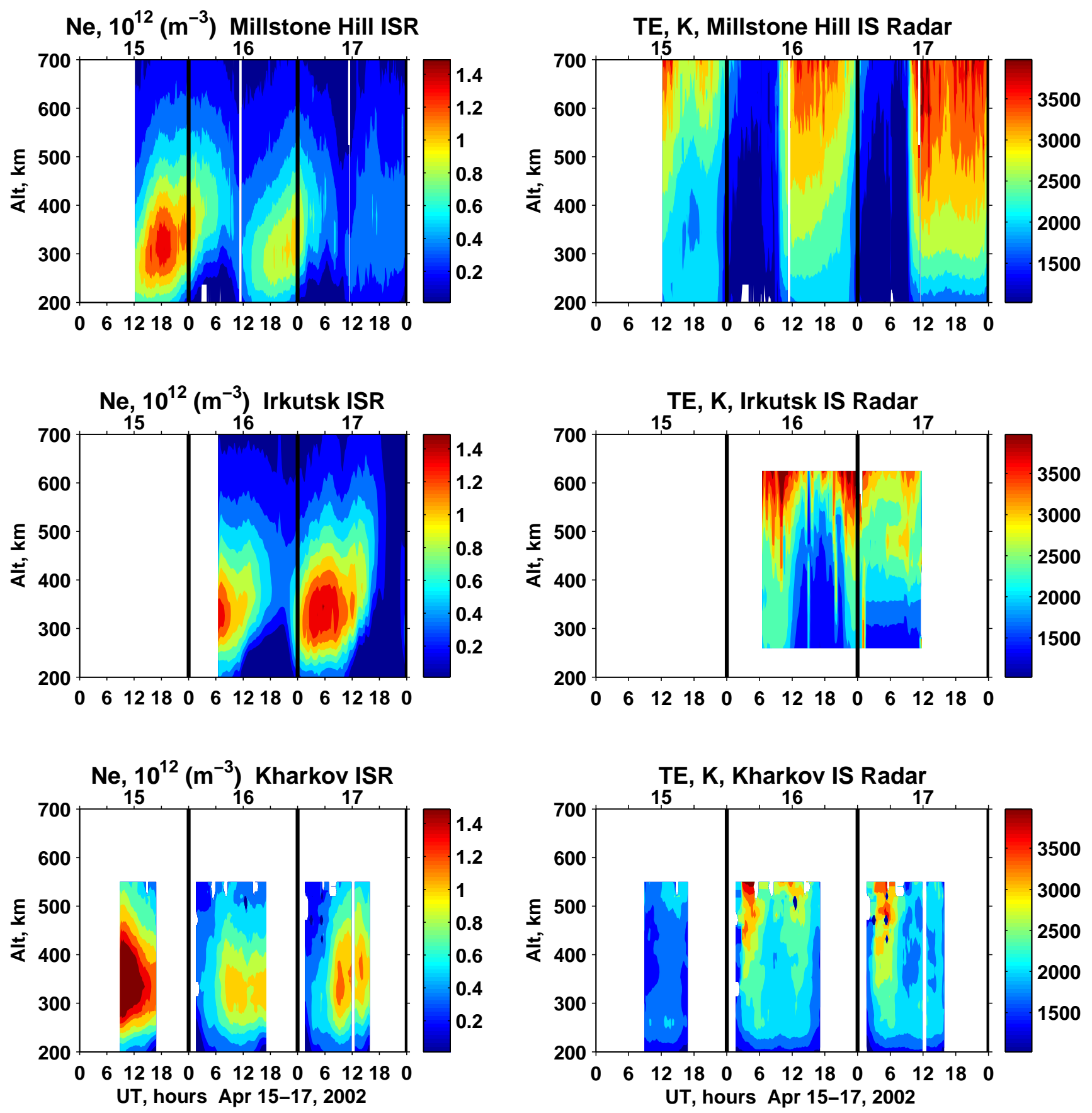

Fig. 7. Variations in the electron density (left panel) and electron temperature (right panel) on 15-17 April 2002 at mid-latitude locations Millstone Hill (top), Irkutsk (middle), and Kharkov (bottom).

On the storm day 17 April, the electron density over Irkutsk is generally $\sim 15 \%$ higher compared to 16 April, and a secondary evening maximum (which happened to be right after the storm onset) is more pronounced. As higher electron density is observed throughout the whole day, mostly at altitudes above the F-region maximum, it cannot be unambiguously attributed to geomagnetic influence, but could result from increased equatorward thermospheric wind (or decreased poleward wind) flow on that day. As the storm develops and the radar rotates to the nightside, the electron density is depleted by a factor of $\sim 2$ due to changes in neutral composition. The electron density remains low on 18 April, and further depletions in both day and nighttime are observed at Irkutsk on 19 and 20 April (see Fig. 9).

Similar to the observations over Irkutsk, the electron density on 17 April over Kharkov is slightly $(\sim 15 \%)$ increased compared to 16 April, which could be part of quiet-time variations related to changes in the neutral density and plasma 
motion. Soon after the storm onset, the density is increased even more at altitudes above the F-peak (Figs. 7 and 9), suggesting that it results from increased upward motion. As the storm progresses, an area of depleted density develops below the F-peak, while density above the F-peak is reduced compared to the time just after the storm onset. In this case, the overall changes in density are minor, as they result from counteracting mechanisms, namely upward motion increasing the electron density and composition disturbances decreasing it. Such locations with minor $(<10 \%)$ variations in electron density are often observed at mid-latitudes, and physical mechanisms for these variations are described by Danilov (2001).

Large differences in the mid-latitude F-region response to a geomagnetic storm are hardly surprising given the fact that the three mid-latitude radars are located at close geographic latitudes, but are at distinctively different geomagnetic latitudes. The Millstone Hill radar, located at $53.4^{\circ}$ magnetic latitude, and at the longitude closest to the magnetic pole, shows the overwhelmingly strongest response to the storm, since one might expect stronger disturbances in neutral composition and thermospheric circulation at that location. On the other hand, smaller responses at Irkutsk and Kharkov, both located at $\sim 46^{\circ}$ magnetic latitude, show that during this storm, major disturbances in wind and composition have not reached this latitude, at least for the first several hours of the storm.

Another major factor affecting the manifestation of storm effects is the location of the observed region in the local time zone during the main phase of the storm. If we follow Szuszczewicz et al. (1998) and define the main phase of the storm as the time period when $D_{s t}<-50 \mathrm{nT}$ and decreasing, the start time for the main phase of the storm will be UT=16:00, and the main phase lasts only for $\sim 2 \mathrm{~h}$ before the recovery begins. This main phase interval corresponds to $\mathrm{LT}=18: 00-20: 00$ over Kharkov, $\mathrm{LT}=23: 00-01: 00$ over Irkutsk and LT=11:00-13:00 over Millstone Hill, i.e. Kharkov was approaching the sunset period, while Irkutsk was in the nighttime, and Millstone Hill was in the midday period. From simulations of ionospheric and thermospheric responses to different storm onset times for the equinox period during high solar activity, Fuller-Rowell et al. (1994), conclude that maximum composition changes can be expected at locations closest to the magnetic pole, and when the magnetic pole is on the nightside during the main phase of the storm. On the other hand, regions located on the dayside and further away from the magnetic pole should have the minimum response to the storm. Observations over Kharkov agree well with such conclusions, showing the smallest initial response to the storm. Unfortunately, further development of the storm events is not possible to discuss as the Kharkov radar stopped taking data shortly after 16:00 UT. At the Irkutsk location, the initial increase in electron density quickly diminishes after the beginning of the main phase of the storm. A deep negative phase with a decrease in electron density by a factor of $2-3$ is observed during local night and well after the local sunrise, as it corotates with
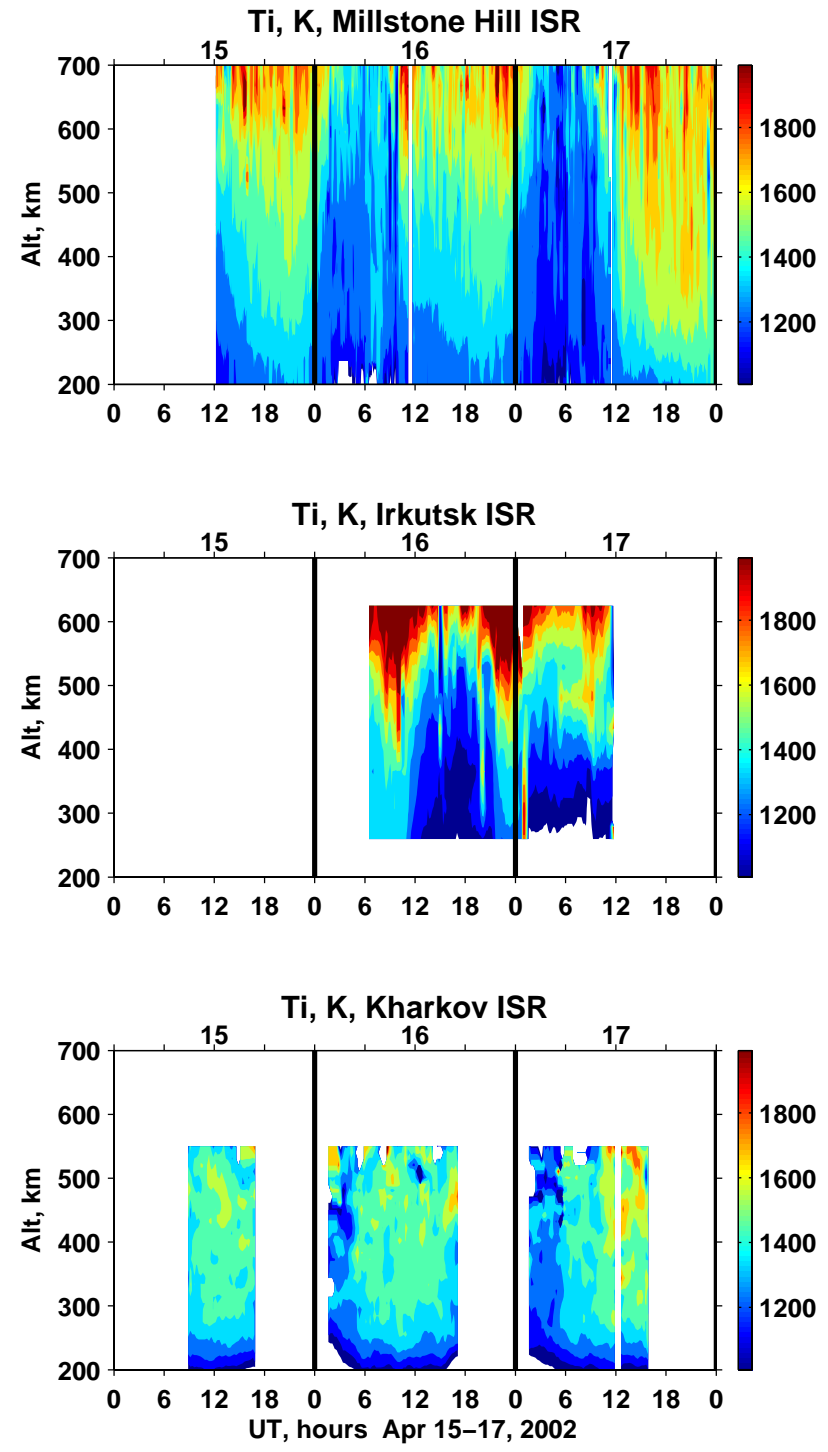

Fig. 8. Variations in ion temperature on 15-17 April 2002 at mid-latitude locations Millstone Hill (top), Irkutsk (middle), and Kharkov (bottom).

the Earth into the daytime hemisphere. These findings agree well with analysis of three magnetic storms by Szuszczewicz et al. (1998), who pointed out that at middle latitudes negative storm phases always begin in the night-time period. In contrast, a strong negative phase is observed at Millstone Hill during local daytime, illustrating that during geomagnetic storms the Millstone Hill location exhibits characteristics which are closer to high-latitude regions than to midlatitude regions. In fact, the reduced rate of rise in electron density immediately after the storm onset (local morning), and the rapid storm-time increase in ion temperature by 200 . . $300 \mathrm{~K}$, suggest that the important mechanism responsible for initial changes in the electron density is the electrodynamic heating due to increased electric fields, similar to high latitudes. Additional mechanisms involving changes 

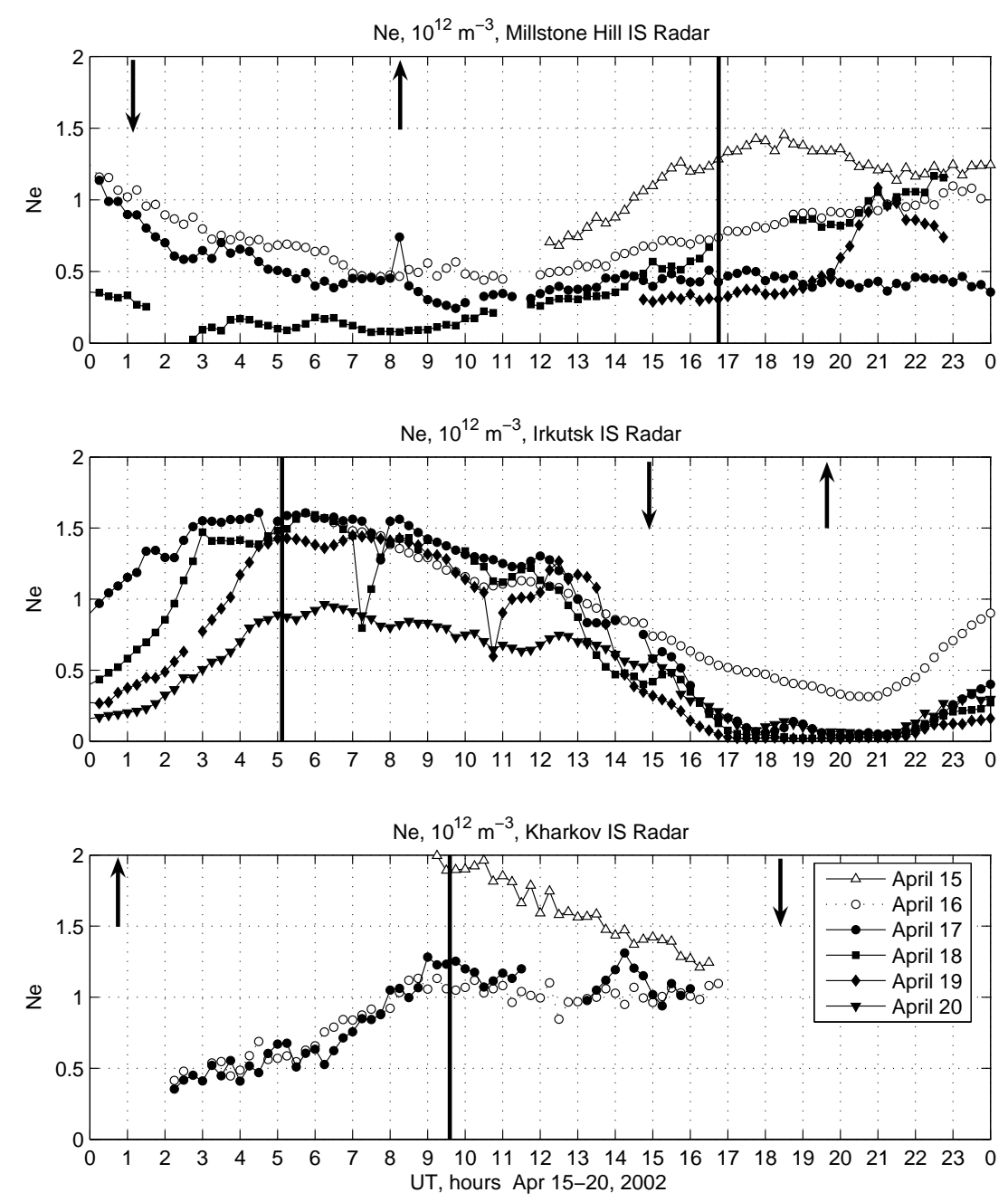

Fig. 9. Electron density measured at $\sim 350 \mathrm{~km}$ by Millstone Hill ISR (top), Irkutsk ISR (middle), and Kharkov ISR (bottom). Vertical lines show local noon for each location, while arrows indicate sunrise (up) and sunset (down) times at $350 \mathrm{~km}$ altitude.

in the neutral composition and meridional wind transport require some time to penetrate from high to lower latitudes, and their contributions are stronger as the storm develops.

It is worth noting that, although the storm occurred on 17 April which is chronologically close to equinox conditions, the transition from equinox to solstice thermospheric circulation is expected to have been completed, and the Northern Hemisphere has a circulation typical for summer conditions (Roble, 1975). In the summer hemisphere, the background thermospheric circulation is directed equatorward throughout the day. It coincides with equatorwarddirected motion brought about by the geomagnetic disturbance, thus allowing such disturbances to propagate to lower latitudes and generate depletions in $\mathrm{O} / \mathrm{N}_{2}$ and, therefore a decrease in the electron density. Such a decrease in the summer hemisphere can happen in both day and nighttime, as observed by Millstone Hill radar for this storm.

It should also be noted that a large decrease (almost by a factor of 2) in daytime electron density is observed at Millstone Hill on 16 April (as compared to 15 April), with a density reduction at all F-region altitudes, which suggests that a primary responsible mechanism is the decrease in the $\mathrm{O} / \mathrm{N}_{2}$ ratio (Prölss, 1995). A similar large decrease during this relatively quiet time was observed at the Kharkov ISR, as well as at other mid-latitude locations, as indicated in the data from ionospheric sounders. This phenomenon is the subject of a separate study (Goncharenko et al., submitted, 2004 ${ }^{1}$ ), as the magnitude of the decrease by far exceeds the usual 10-30\% quiet-time variations (Forbes et al., 2000; Rishbeth and Mendillo, 2001). However, it is important to remember that storm-induced changes in ionospheric parameters occur in addition to large quiet-time variations observed during this period, and the storm-induced changes can often be masked or cancelled by these variations.

\footnotetext{
${ }^{1}$ Goncharenko, L., Salah, J., Crowley, G., Paxton, L., Zhang, Y., Coster, A., Rideout, W., Huang,C., Zhang, S., Reinisch, B., and Taran, V.: Variability in the thermosphere and ionosphere during minor geomagnetic disturbances and its association with IMF By orientation, J. Geophys. Res., 2004JA010683, submitted, 2004.
} 

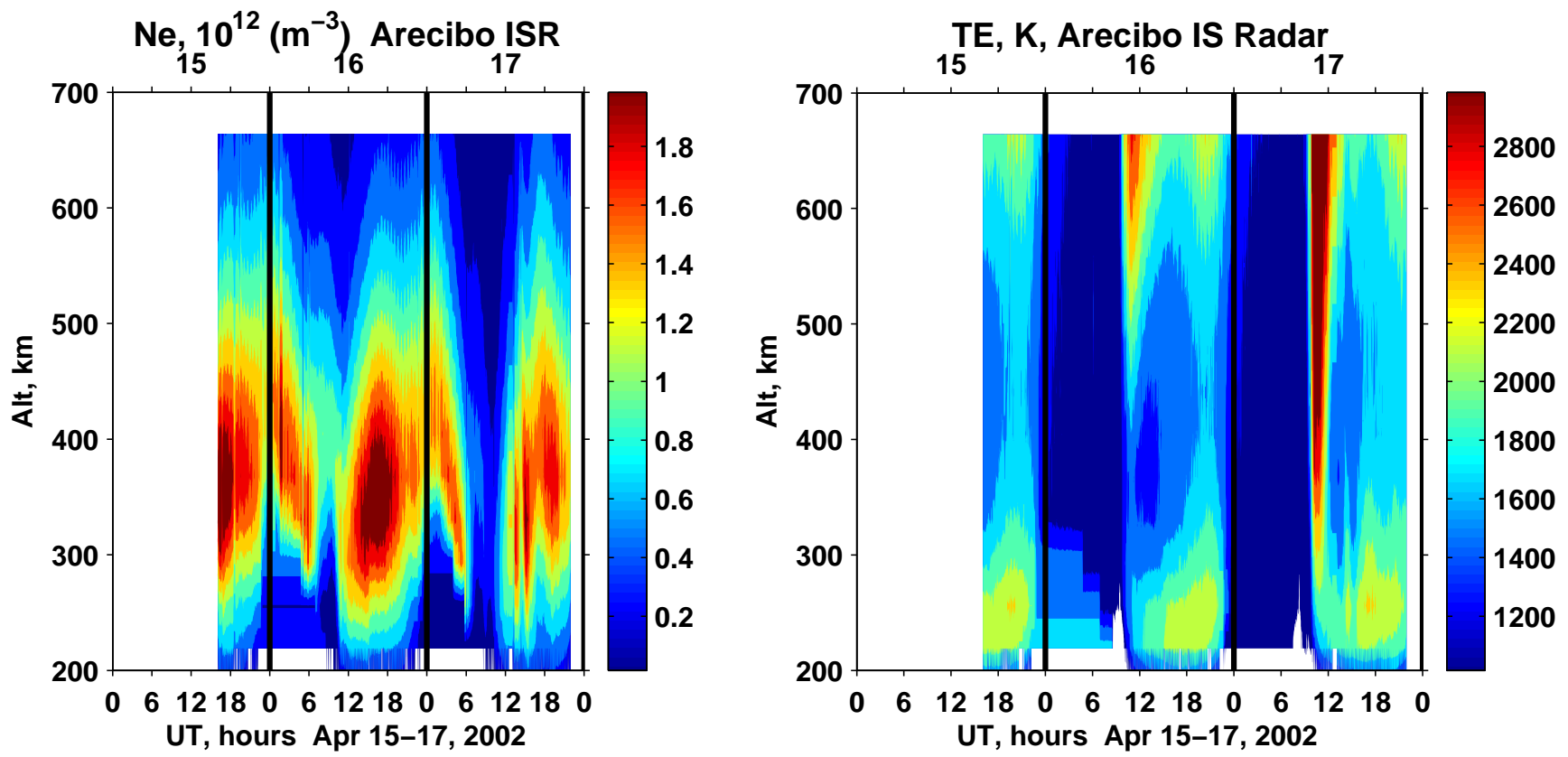

Fig. 10. Variations in the electron density (left panel) and electron temperature (right panel) on 15-17 April 2002 at Arecibo.

\subsection{Latitudinal variations}

As discussed earlier, the chain of incoherent scatter radars near the $70^{\circ} \mathrm{W}$ meridian provides a unique opportunity to characterize the propagation of storm disturbances from the auroral zone to the equator. In previous sections, we discussed effects in the auroral zone/polar cap boundary as observed by Sondrestrom, and the effects in the subauroral region as observed by Millstone Hill. Here we start with a description of data obtained at Arecibo and Jicamarca, and then examine the propagation of disturbances in latitude using drift data from the radars along the $70^{\circ} \mathrm{W}$ meridian.

\subsubsection{Latitudinal variations in ionospheric parameters}

Typically, the behavior of ionospheric parameters above Arecibo shows a marked difference from other mid-latitude locations, which results from the unique combination of features of low geodetic latitude $\left(18.34^{\circ} \mathrm{N}\right)$ and middle geomagnetic latitude $\left(\sim 32.17^{\circ} \mathrm{N}\right)$. Some of the most distinctive features of the quiet-time ionosphere observed above Arecibo during 15-17 April 2002 are shown in Figs. 10 and 11. These include a night-time enhancement in $N m \mathrm{~F} 2$ observed between 0 and $\sim 06: 00 \mathrm{UT}$, with the height of the layer rapidly descending from $\sim 440 \mathrm{~km}$ to $\sim 275 \mathrm{~km}$, and a rapid decrease in electron density by a factor of 2-4 during the time of increase in layer height between 06:00 and 11:00 UT. The drop in the electron density is accompanied by a large increase in electron temperature at 09:00-11:00 UT, and is especially pronounced in the morning of 17 April (Fig. 10, right panel).

The rapid decrease in the height of the F2-layer is the well-known "midnight collapse" of the F-region, which is a typical feature of the Arecibo data observed in $85 \%$ of the nights (Nelson and Cogger, 1971). It is interpreted as a result of upward propagating semidiurnal tidal components (Crary and Forbes, 1986). A particular feature of the April 2002 observations is the unusually long $(\sim 6 \mathrm{~h})$ midnight collapse with a descent by $165 \mathrm{~km}$, compared with a typical descent by $50-100 \mathrm{~km}$, lasting for $1-3 \mathrm{~h}$. Large night-time electron density, noted previously by Burnside et al. (1991a) during high solar activity, could result from the poleward motion of the equatorial anomaly, which normally lies southward from Arecibo.

The primary effects of the geomagnetic storm at Arecibo are rapid variations in the height of the F-layer and in the electron density, as shown in Fig. 11, similar to those observed during the storm of March 1990 (Richards et al., 1994). Variations in the electron density are anti-correlated with variations in the electron temperature around $350 \mathrm{~km}$. This phenomenon was previously studied by Zhou and Sulzer (1997), who suggested that this is a manifestation of photoionization dominating the thermal conduction in heating the electrons. It is interesting to note that the increase in the height of the layer is accompanied by a decrease in the electron density. This is an unusual behavior for the Fregion, as one would expect slower recombination at higher altitudes. Such variations also suggest the dominance of plasma transport at Arecibo's location over both production and recombination. The contributions to the plasma transport could come from both disturbance neutral winds and magnetospheric electric field penetration, and the importance of both mechanisms for the ionosphere over Arecibo was discussed by Buonsanto et al. (1993). Variations in the eastward electric field could push the equatorial anomaly to higher 

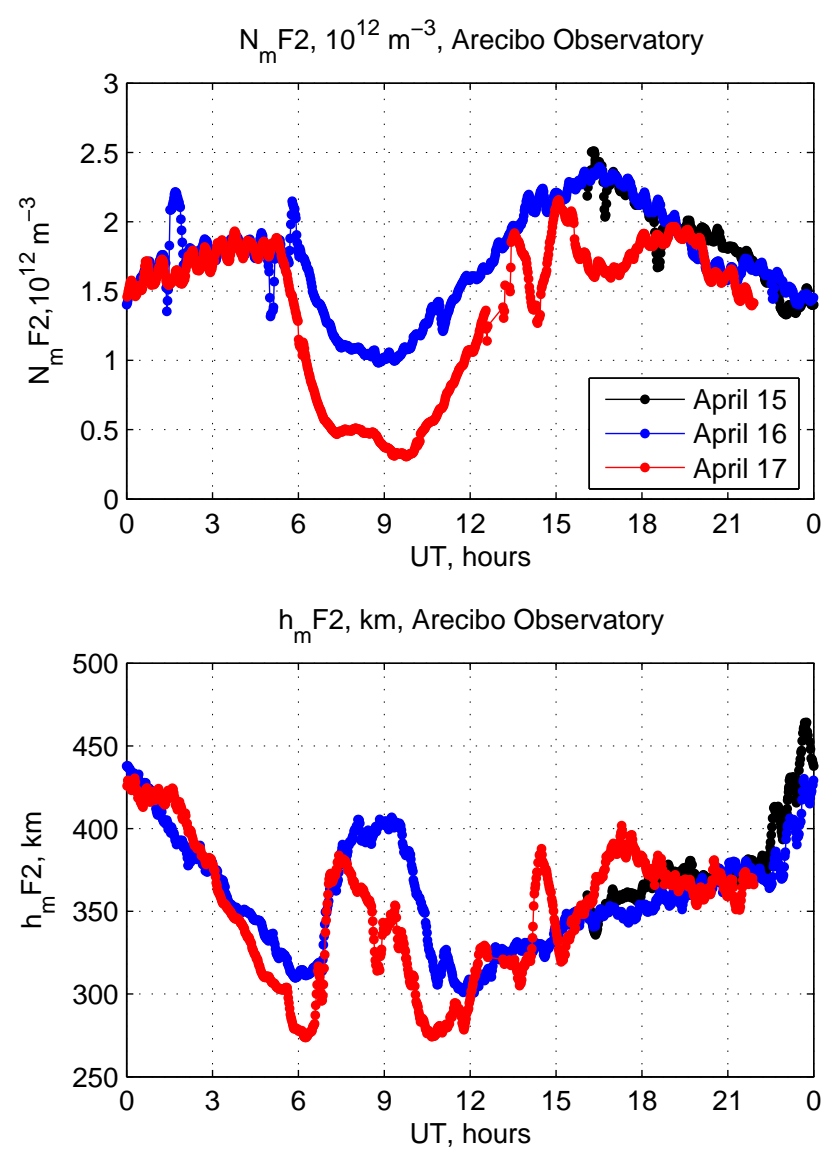

Fig. 11. Electron density at the peak of the F-layer $N m \mathrm{~F} 2$ (top) and the height of the F-layer $h m \mathrm{~F} 2$ (bottom) at Arecibo for 15-17 April 2002.

or lower latitudes, as happened in cases studied by Buonsanto et al. (1999b) and Aponte et al. (2000). Travelling atmospheric disturbances, launched by high-latitude heating events, could cause fluctuations in $h m \mathrm{~F} 2$ by raising the height of the layer (e.g. Buonsanto et al., 1999a). The exact contributions from these mechanisms, as well as from changes in the atomic oxygen density (i.e. Burnside et al., 1991b), require a separate study through modeling of the storm effects.

To discuss the ionospheric reaction to this storm at equatorial latitudes, we use vertical ion drift data (i.e. eastward electric field) with 5-min resolution from the Jicamarca incoherent scatter radar (Fig. 12, top panel) and electron density data with 15-min resolution from the Jicamarca digisonde (Fig. 12, middle and bottom panels). During the quiet time, ionospheric behavior is typical for equatorial latitudes, with a high daytime density and a "bite out" in density near local noon, produced by the fountain effect (Adeniyi, 1986; Prölss, 1995). The eastward electric field (i.e. vertical ion drift for Jicamarca's dip latitude) is of the order of $\sim 0.6 \mathrm{mV} / \mathrm{m}$ $(\sim 25 \mathrm{~m} / \mathrm{s})$ in daytime, and is slightly higher and negative at night. The prereversal enhancement is found to be well pronounced at 23:00-24:00 UT, as expected for high solar
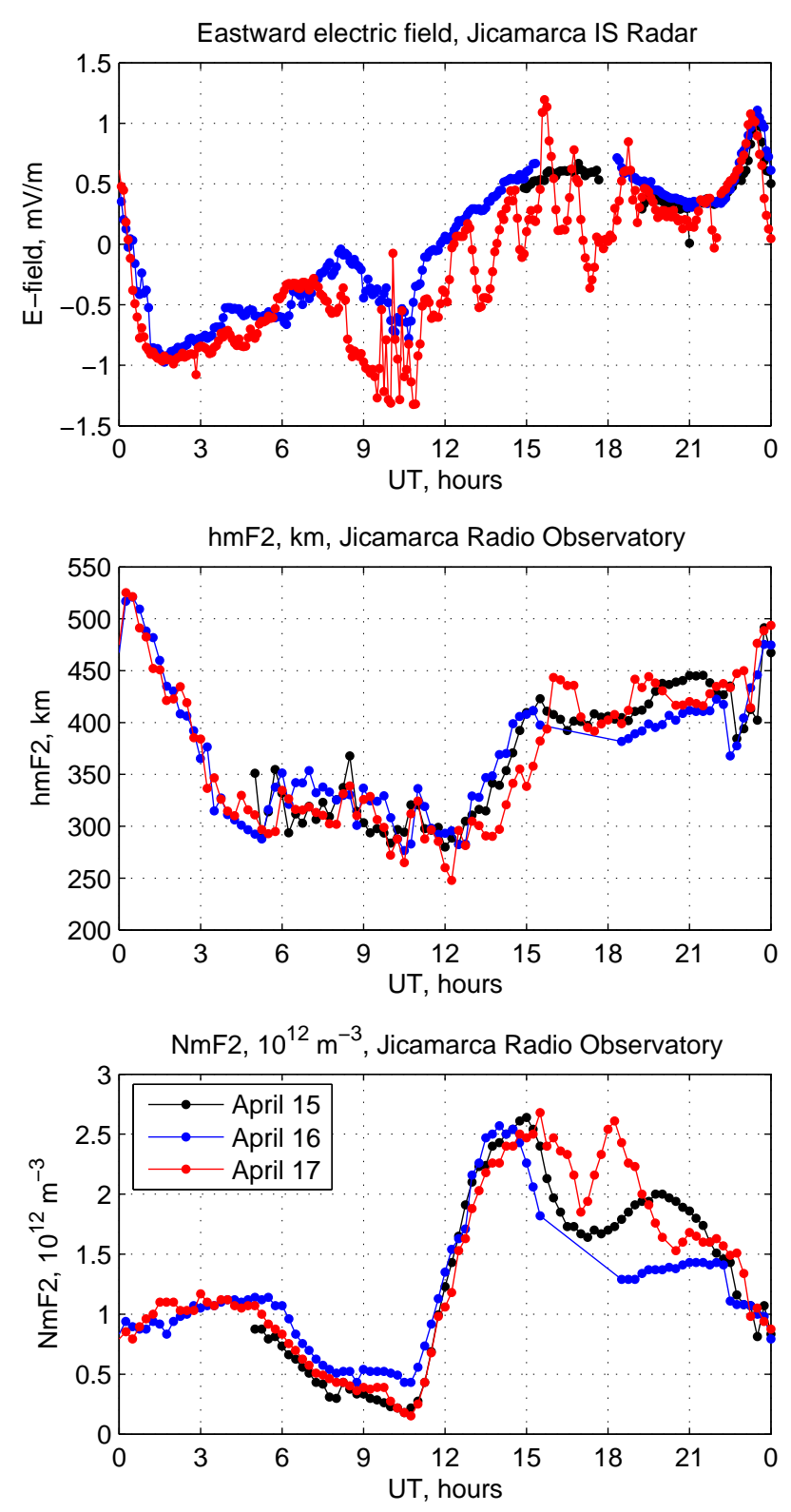

Fig. 12. Ionospheric parameters observed over Jicamarca on 15-17 April 2002: eastward electric field (top panel), height of the F-layer $h m \mathrm{~F} 2$ (middle panel), and electron density at the peak of the F-layer $N m \mathrm{~F} 2$ (bottom panel).

activity (Fejer et al., 1991). The most pronounced response to geomagnetic activity on 17 April 2002, is the increase in $N m$ F2 between $\sim 15: 30$ and 19:00 UT, i.e. close to the main phase of the storm, leading to a reduction in the noon "biteout". After 21:00-22:00 UT, $N m$ F2 returns to the levels observed before the storm. This is the most common response of the equatorial ionosphere to a geomagnetic storm, as a daytime increase in electron density is reported in $88 \%$ of the cases (Adeniyi, 1986; Mikhailov et al., 1994).

One of the interesting features of the equatorial ionosphere is its reaction to the penetration electric field. An abrupt 
northward swing in $B_{z}$ produces a large and sudden drop in the cross polar cap potential and the penetration of a westward electric field to the equator (e.g. Sastri et al., 1992). On 17 April 2002, the electric field penetration event was unusually long with an $\sim 1.5$-h quasi-periodic signature, as discussed by Kelley et al. (2003) and shown in Fig. 12 (top panel). The quasi-periodic variations in the eastward electric field are superimposed on a generally smaller day-time electric field, which could correspond to contributions from the changes in the neutral wind dynamo as commonly observed in the equatorial ionosphere during storm periods (e.g. Fejer, 1981; Fejer et al., 1991; Fejer and Scherliess, 1995). This results in an overall $50-60 \mathrm{~km}$ decrease in $h m \mathrm{~F} 2$ on 17 April as compared to the two previous days, with sharp changes in the height of the F2-layer following variations in the electric field (Fig. 12, middle panel). It contrasts with the smooth post-sunrise increase in $h m \mathrm{~F} 2$ observed on 15-16 April 2002. The effects of an eastward electric field pushing F-region plasma upwards are especially clear between 15:00 and 16:00 UT, when the height of the layer increases by over $100 \mathrm{~km}$. The resulting changes in the electron density are most pronounced after 15:00 UT. The decrease in the upward drift results in the $N m \mathrm{~F} 2$ increase and in diminishing of the "bite-out", while enhancement in the vertical drift brings the electron density lower as it moves along the magnetic field lines away from the equatorial region.

\subsubsection{Plasma drifts and their effects}

Figures 13 and 14 show the plasma drift measurements from the incoherent scatter radars in the North American sector. Electric fields were derived from the plasma drift vector observations and are given in Fig. 13 for the eastward and northward components for 15, 16, and 17 April 2002, with the former two days providing a reference for the disturbance effects on 17 April. The eastward electric field data from higher latitudes correlates well with the eastward electric field from Jicamarca (Fig. 12), as pointed out by Kelley et al. (2003) (see Kelley et al., 2003, Fig. 3). However, only the main features of the Jicamarca disturbance eastward electric field can be tracked at Sondrestrom, Millstone Hill and Arecibo due to the lower time resolution at these radars. The eastward electric field at Sondrestrom reveals oscillations in the electric field at the storm onset time, reaching values of $60 \mathrm{mV} / \mathrm{m}$ at about 12:30 UT, mostly in the eastward direction. The presence of an oscillation is also seen in the eastward electric field at Millstone Hill, with a peak of $5 \mathrm{mV} / \mathrm{m}$ at 12:30 UT that is clearly apparent relative to the quiet-time period on 16 April. Arecibo's electric fields remain small, less than $1 \mathrm{mV} / \mathrm{m}$, but an oscillation can be traced after the storm onset. Clearly, the observations support the indication of penetrating electric field disturbances from high latitude to the equatorial region. The Jicamarca observations have been correlated by Kelley et al. (2003) with measurements of the electric field in the solar wind by the ACE satellite, and have been used to demonstrate the coupling of the magnetospheric fields and their penetration to equatorial latitudes.
The northward electric field (Fig. 13, right panel) also shows large variations, with the Sondrestrom radar indicating a southward perturbation of about $100 \mathrm{mV} / \mathrm{m}$ within an hour of storm onset, peaking at 12:00 to 13:00 UT. Millstone Hill observes a $10 \mathrm{mV} / \mathrm{m}$ perturbation at that time, with a clear difference from the quiet conditions of the previous days. Reaction to the storm in the northward electric field is not as clearly apparent at Arecibo, but oscillations are seen a few hours later than storm onset. The intense increase of the electric fields at Sondrestrom leads to the large frictional heating in the ion temperatures shown in Figs. 4 and 6 and discussed previously. Similar responses of the ion temperatures are seen for Millstone Hill (Fig. 8), while the ion temperature at Arecibo is consistent with the absence of large electric field perturbations.

Finally, Fig. 14 shows the ion drift parallel to the magnetic field line at an altitude of $300 \mathrm{~km}$ for the Sondrestrom, Millstone Hill and Arecibo radars, and compares the 17 April drifts with those observed on the quieter days on 15 and 16 April. The primary feature to be noted from these observations is the large enhancement in the ion drifts along the field lines. The downward drift reaches $150 \mathrm{~m} / \mathrm{s}$ at Sondrestrom, while the upward drift reaches $60 \mathrm{~m} / \mathrm{s}$ at Millstone Hill and $30 \mathrm{~m} / \mathrm{s}$ at Arecibo, with all stations revealing large oscillations after storm onset. The upward plasma drifts are caused by southward neutral winds. The observations in Fig. 14 suggest that the large equatorward winds are generated as a result of the storm and are coupled with a traveling atmospheric disturbance. Although daytime equatorward wind surges are relatively rarely observed, they have been documented in previous storm observations (e.g. Buonsanto et al., 1989) and models (e.g. Roble et al., 1987; FullerRowell et al., 1996), and are consistent with the observed uplifting of the F-layer height at the mid-latitude radars, e.g. Irkutsk and Kharkov in Fig. 7, as discussed in Sect. 2.3 of this paper. Figure 14 also suggests that surges in the equatorward wind cover large latitudinal region and take $\sim 50-70 \mathrm{~min}$ to travel from Millstone Hill to Arecibo.

The experimental data presented above illustrate large and complex variability of ionospheric parameters resulting from geomagnetic storms. We will further focus on the characteristics of ionospheric parameters after the storm onset and the main mechanisms responsible for variations in these characteristics.

Our observations of the initial response of the ionosphere to the storm show a complex pattern of disturbances in plasma drifts. Of particular interest is a perturbation in the eastward electric field, which consists of long-lasting (several hours) variation superimposed on sharp and short-lived (less than an hour) disturbances. This perturbation is observed by all radars along $70^{\circ} \mathrm{W}$ longitude, as shown in Figs. 12 and 13. Both types of disturbances result mostly from the prompt penetration of magnetospheric electric fields from high to low latitudes. Both short-lived disturbances and longer-lasting disturbances in the zonal electric field were extensively studied through observations and models (Kelley et al., 1979; Spiro et al., 1981; Wand, 1981; Fejer and 

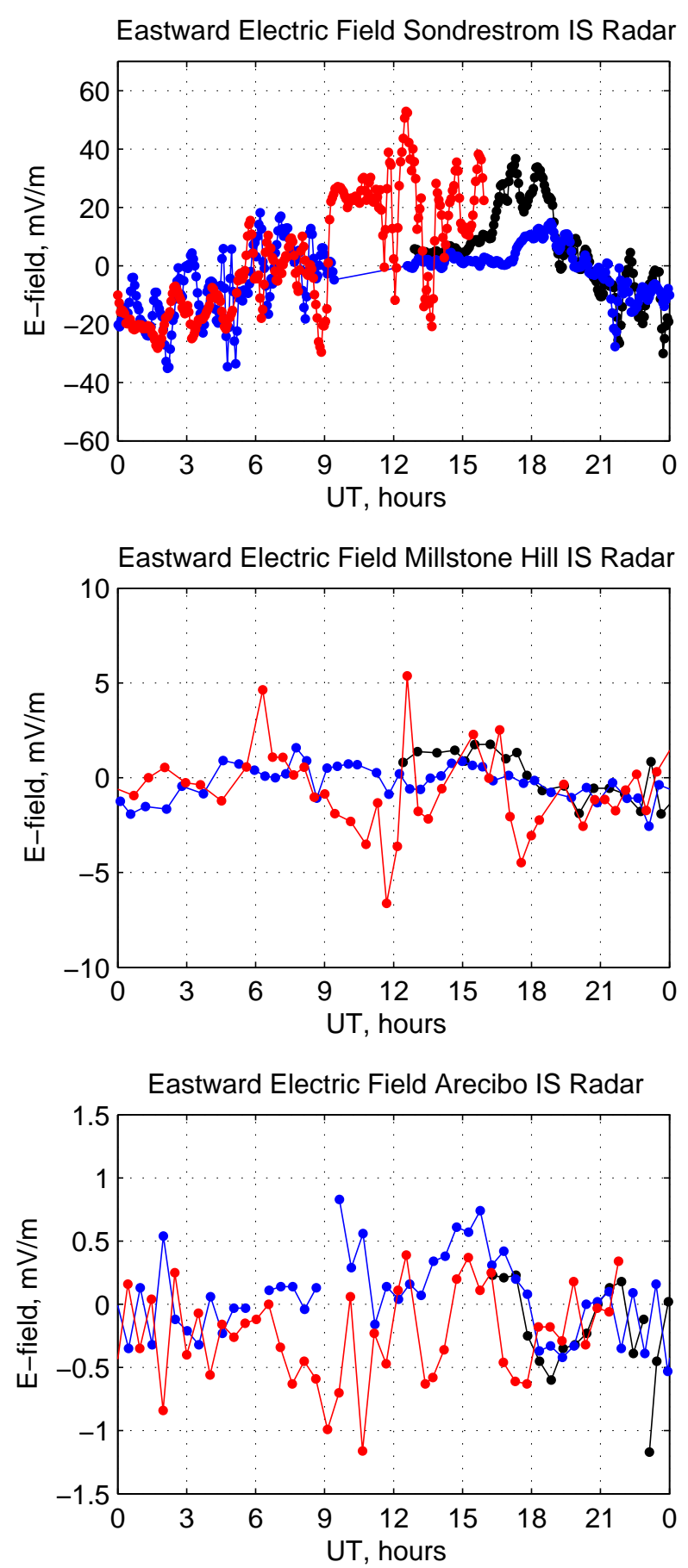
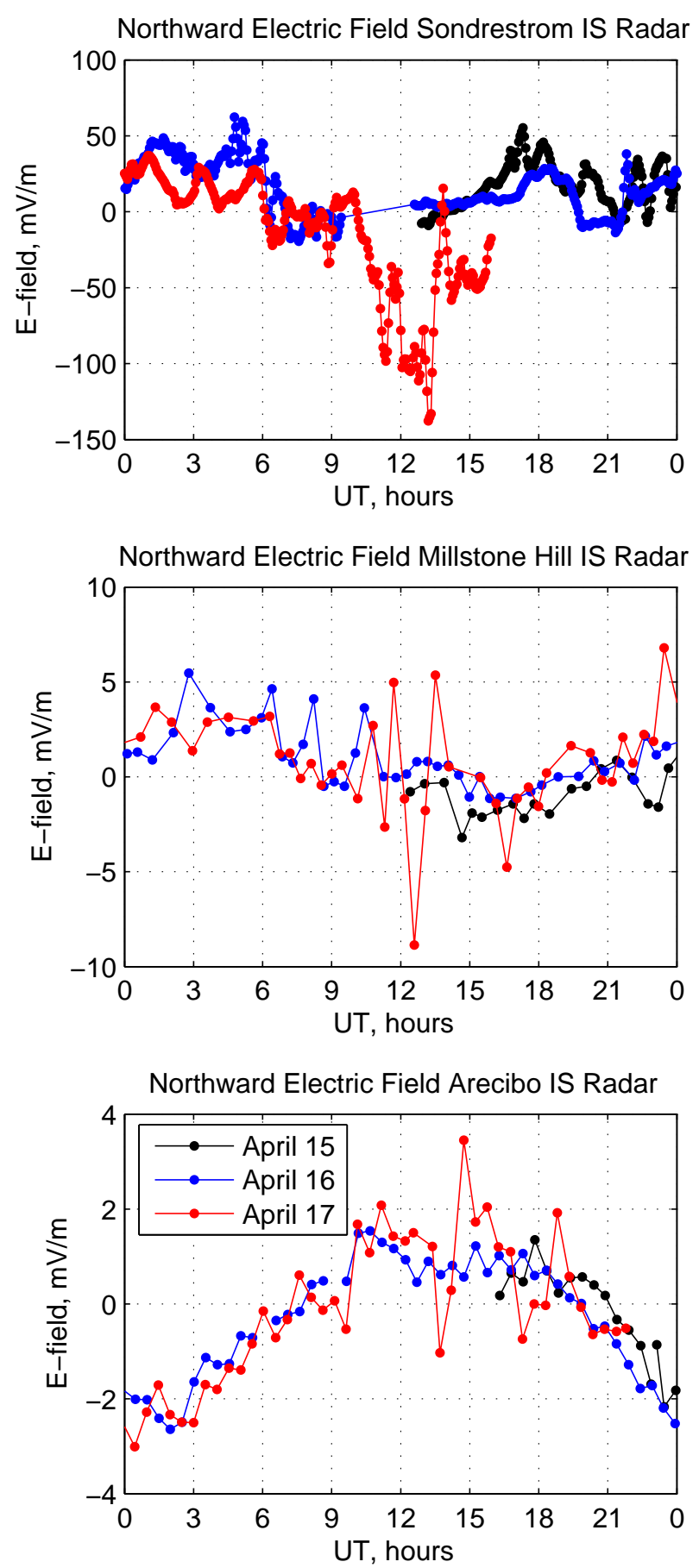

Fig. 13. Eastward (left panel) and northward (right panel components of local electric field observed over Sondrestrom (top), Millstone Hill (middle) and Arecibo (bottom).

Scherliess, 1998; Scherliess et al., 2001). Experimental data show that storm-time penetration electric fields can significantly depart from the average climatological pattern, and the sources of the large variability are not well understood (Fejer, 2002). While many questions remain, the average behavior of the disturbance electric field has well-defined trends. It is characterized by an eastward electric field in the afternoon and pre-midnight sector, and a westward electric field in the morning sector (Wand, 1981; Scherliess et al., 2001). It also shows a clear dependence on the level of geomagnetic activity, and for $K_{p}=5$ conditions and magnetic latitude $56^{\circ}$, the average penetration electric field reaches $\sim 2 \mathrm{mV} / \mathrm{m}$ in the afternoon sector and $\sim 3 \mathrm{mV} / \mathrm{m}$ in the morning sector (Wand, 1981).

A sustained increase in the zonal electric field has important consequences for ionospheric electron density. A zonal 
electric field corresponds to plasma transport in the meridional direction, and combined with the magnetic field, causes vertical plasma transport. Depending on the direction, it can lead to a rapid increase or decrease in the height of the Flayer, and, hence to an increase or decrease of electron density (positive or negative storm effects). Recently, Sojka et al. (2002) used Utah State University ionospheric model to simulate the effects of long-lasting penetration electric fields on the mid-latitude ionosphere. They concluded that a penetration electric field with magnitudes according to Wand (1981), i.e. $2-3 \mathrm{mV} / \mathrm{m}$, can be responsible for a factor of 10 increase in the electron density in the pre-midnight sector, a factor of 10 decrease in the electron density in the pre-dawn sector, and tens of percent decrease in the electron density in the pre-noon sector.

On 17 April, the $\sim 70^{\circ} \mathrm{W}$ radar chain observes penetration electric fields from $\sim 07: 00-08: 00$ UT to $\sim 18: 30$ UT (see Figs. 12 and 13), i.e. radars are located in the morning and noon sectors. The direction and magnitude of the penetration electric field is close to the average behavior, and a significant decrease in the electron density is observed at mid-latitude location at Millstone Hill, as predicted by Sojka et al. (2002). Figure 15 shows more detailed data for Millstone Hill to illustrate this effect. For convenience, the top part of the Fig. 15 shows the eastward electric field (as given in Fig. 13), followed by the meridional neutral wind at $\sim 300 \mathrm{~km}$ (northward positive), the height of the F-region peak $h m \mathrm{~F} 2$, and the electron density at the peak $N m \mathrm{~F} 2$. The meridional neutral wind is derived from the ISR ion drift vector measurements (e.g. Buonsanto and Witasse, 1999). Vertical lines indicate local noon, and arrows show sunrise and sunset times at $300 \mathrm{~km}$. As was noted in Sect. 2.3, the daytime electron density on 16 April was unusually low and cannot serve as an indicator of quiet-time behavior. The solid line in the bottom panel of Fig. 15 presents the average quiet time $N m \mathrm{~F} 2$, obtained from the Millstone Hill digisonde for 1-15 April 2002.

On 17 April, a decrease in electron density above Millstone Hill is observed starting after 09:00 UT. It results from several competing processes, as follows from the presented data. The westward penetration electric field causes downward plasma flow and aids in the decrease in electron density. However, an equatorward neutral wind, observed from $\sim 9: 30$ to $\sim 16: 00$ UT (Fig. 15, second panel), counteracts this mechanism as it pushes plasma up the field line. Rapid changes in both electric field and meridional wind result in a very dynamic behavior of $h m \mathrm{~F} 2$. In addition, an increase in plasma temperature due to electrodynamic heating (Fig. 8) leads to higher recombination and reduces electron density. In contrast, at the mid-latitude locations of Kharkov and Irkutsk, which are in the afternoon sector after the storm onset, the same long-lasting penetration electric field would be directed eastward. Upward plasma motion due to the eastward electric field, in combination with upward motion due to the equatorward wind, causes positive storm effects at these locations (Figs. 7 and 9). At lower latitudes, the efficiency of the penetration electric field on plasma motion
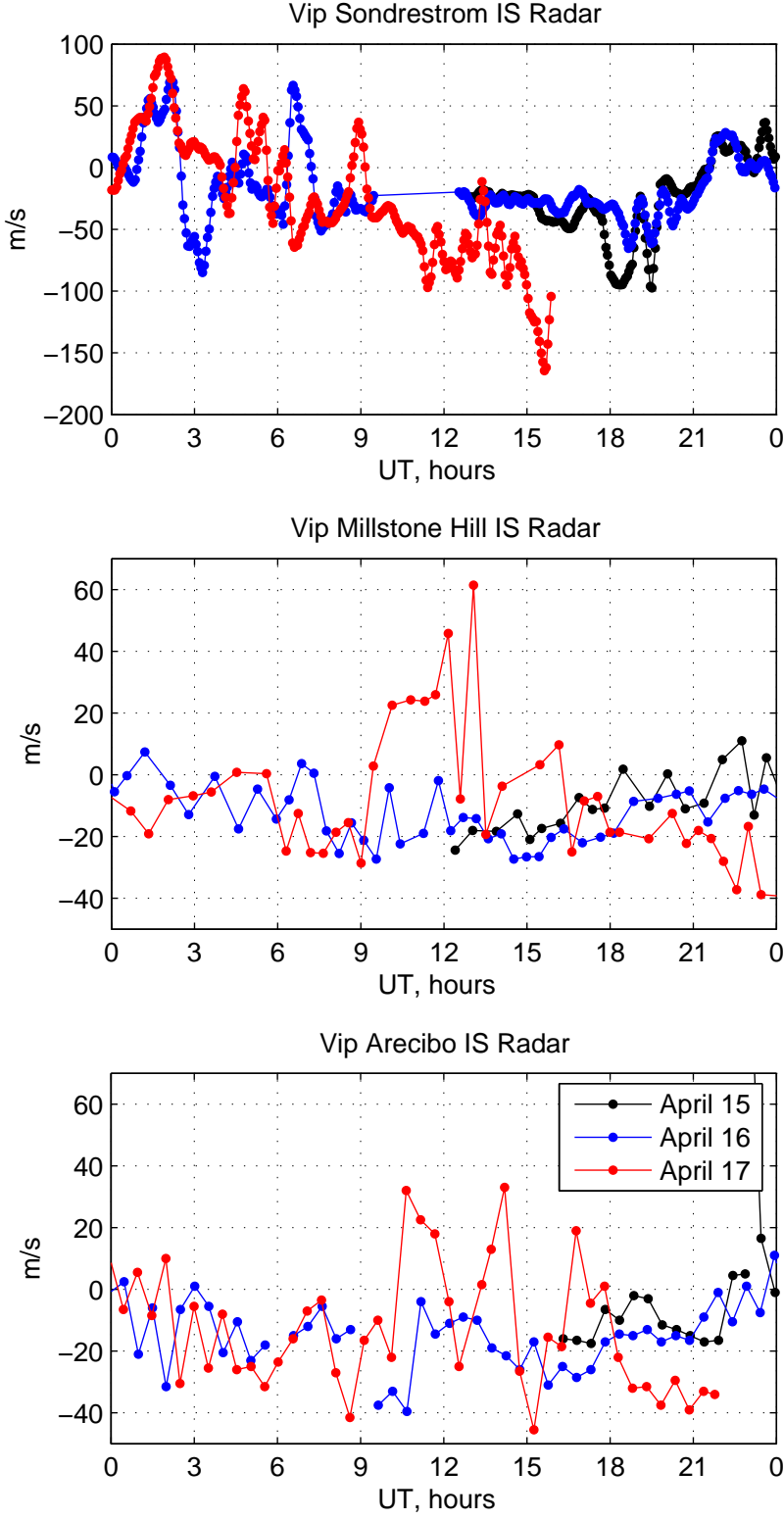

Fig. 14. Parallel ion drift measured between 300 and $400 \mathrm{~km}$ at Sondrestrom (top), Millstone Hill (middle) and Arecibo (bottom).

increases due to the dip angle, while the efficiency of equatorward wind decreases. Observations over Arecibo suggest that the penetration electric field is indeed an important mechanism, responsible for the decrease in electron density at this location (Figs. 11, 13, 14).

\section{Conclusions}

The observational data obtained by eight incoherent scatter radars during the April 2002 campaign provide simultaneous information on the ionosphere-thermosphere system at a variety of local times and locations. Combined with unprecedented data coverage by a number of space-based and ground-based instruments, these radar data 


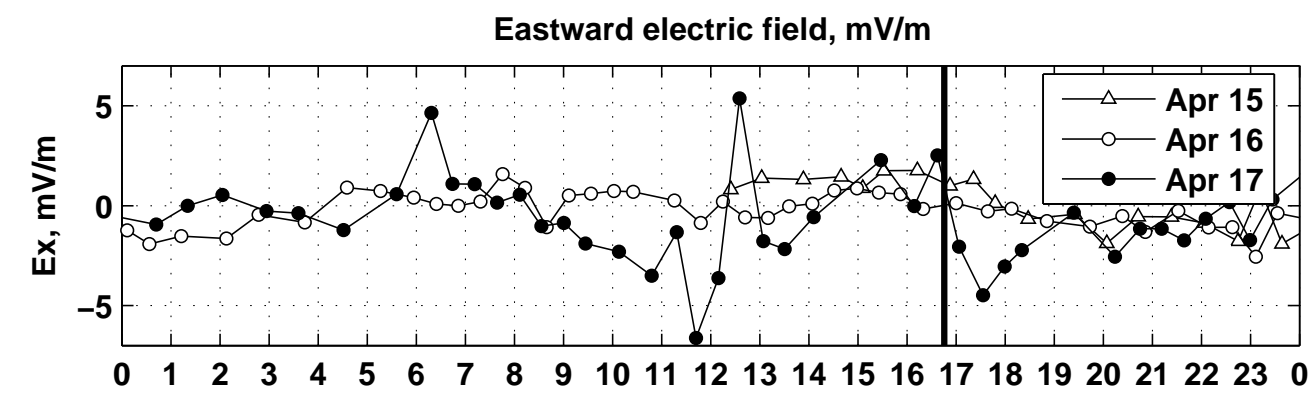

Northward wind, $\mathrm{m} / \mathrm{s}$
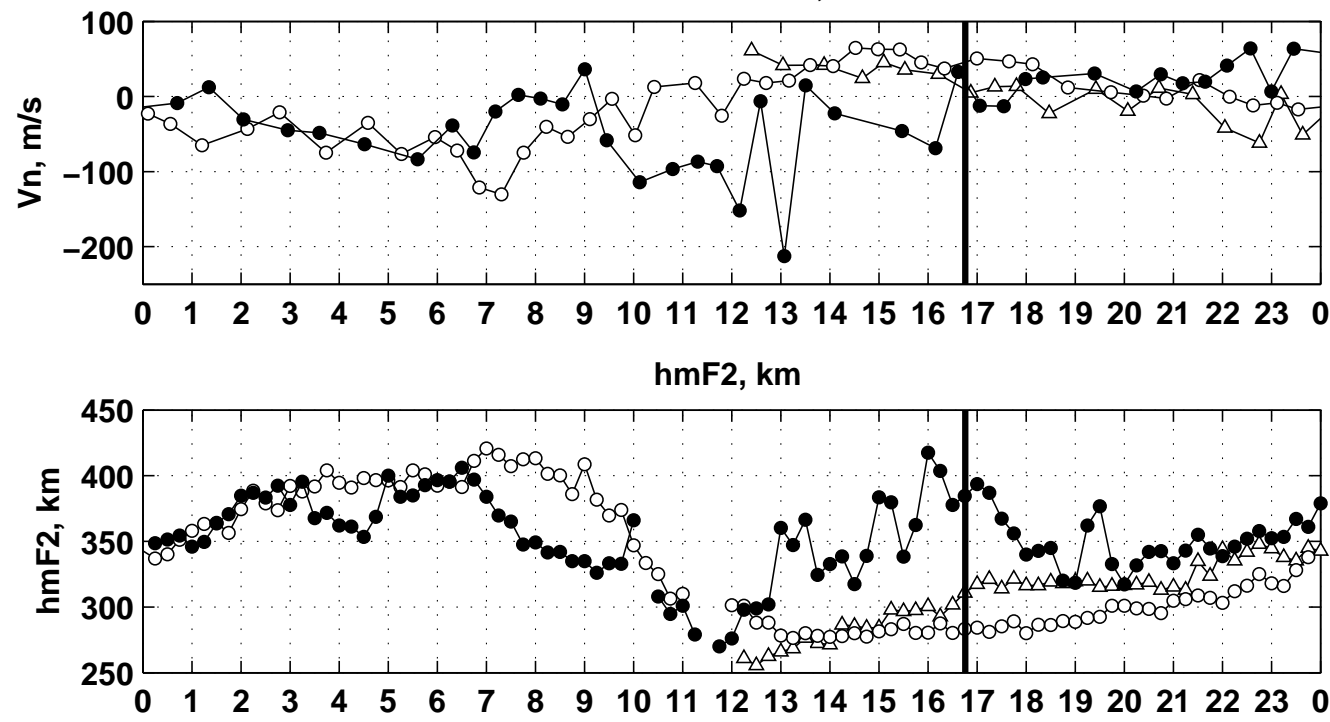

$\mathrm{NmF2}, 10^{12} \mathrm{~m}^{-3}$

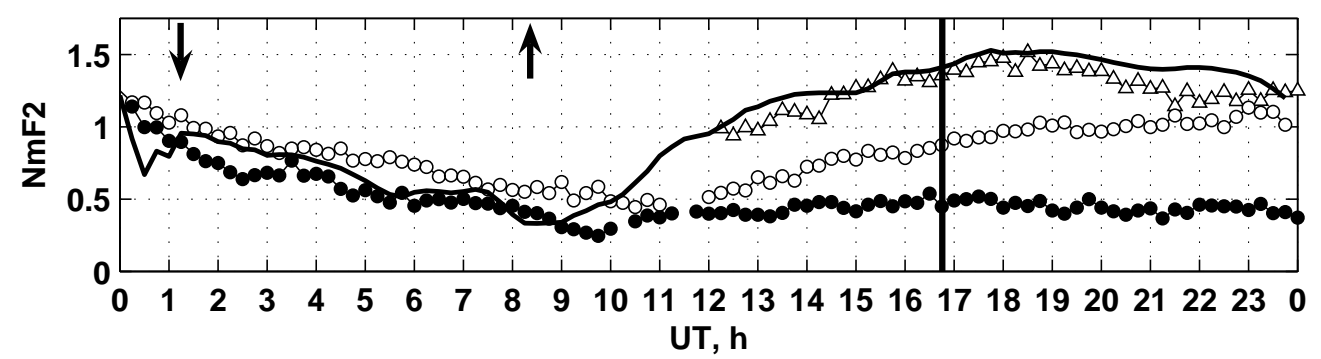

Fig. 15. Ionospheric and thermospheric parameters observed at Millstone Hill: eastward electric field, meridional wind (northward positive), height of the F-layer $h m \mathrm{~F} 2$, and electron density at the peak of the F-layer $N m \mathrm{~F} 2$. Vertical lines indicate local noon, and arrows show sunrise and sunset times at $300 \mathrm{~km}$. Solid line in the bottom panel presents average quiet time $N m \mathrm{~F} 2$, obtained from the Millstone Hill digisonde for 1-15 April 2002.

present a unique opportunity to study the response of the magnetosphere-ionosphere-thermosphere system to geomagnetic disturbances and the propagation of storm effects in latitude and altitude.

The main ionospheric response to the 17 April 2002 geomagnetic storm is a deep negative phase, with the electron density decreasing by a factor of 2-6 at auroral latitudes and by a factor of $2-3$ at subauroral and middle latitudes. In contrast to a number of previous studies, none of the high-latitude radars observed a prolonged increase in the electron density, which means that the auroral oval expanded equatorward and was pushed out of the radars' fields-of-view. The negative phase at high latitudes (Svalbard, EISCAT mainland, Sondrestrom) developed practically instantaneously, signaling that the increased electric field is a primary responsible factor. At middle latitudes, Fregion effects have a longer time to develop, and the negative phase at Irkutsk starts developing after the onset of the main phase of the storm and peaks $\sim 6 \mathrm{~h}$ later. At the sub-auroral latitude of Millstone Hill, the observations combine features of both high and middle latitudes, with a strong initial response and subsequent deeper development of the 
negative phase. Penetration electric field, equatorward neutral wind, and electrodynamic heating are important counteracting mechanisms affecting electron density over Millstone Hill, with electrodynamic heating identified as a dominant mechanism after the storm onset. Small $\sim 15 \%$ enhancements of electron density (positive phase) are noted in the daytime sector at mid-latitudes (Kharkov and Irkutsk) close to 12:00 and 14:00 UT, suggesting that surges in aurorallygenerated equatorward wind and penetration electric fields are likely candidates to explain these observations.

Strong heating of the upper atmosphere is observed at high latitudes, with the western hemisphere (morning sector) being heated more than eastern hemisphere (daytime sector). The Sondrestrom radar recorded an extremely large $(\sim 1000 \ldots 3000 \mathrm{~K})$ increase in ion temperature. The increase in the ion temperature subsides to $\sim 200 \ldots 300 \mathrm{~K}$ at the subauroral latitude of Millstone Hill, and diminishes to a level of day-to-day variations at the lower mid-latitude of Arecibo, where the main response to the storm is an oscillation in Flayer heights by as much as $90 \mathrm{~km}$ and a decrease in the electron density.

The observations also show evidence of magnetospheric electric fields penetrating from high to low latitudes, as well as an increase in the daytime equatorward wind. At middle latitudes, equatorward winds have a maximum lifting effect on ionospheric plasma. While the effects of the equatorward wind become less obvious at lower latitudes because of the low dip angles of the field lines, the importance of electric fields becomes stronger, as evident in the Arecibo and Jicamarca measurements. The presented observations are consistent with model predictions of ionospheric effects produced by penetration electric fields (e.g. Sojka et al., 2002), and highlight the importance of combined effects from other mechanisms.

The data gathered by the incoherent scatter radar network for the April 2002 storm event contribute to the understanding of the phenomena associated with the solar influences on the Earth's upper atmosphere. Analysis work continues in several areas including detailed comparisons of the observations with the predictions from general circulation models, and investigation of the effects in the ionospheric E- and F1- regions, as well as in the lower thermosphere and mesosphere.

Acknowledgements. The analysis of the observations was supported under the CEDAR/TIMED grant (ATM-0000958) from the National Science Foundation (NSF) and the NASA grant NAG513602 to the Massachusetts Institute of Technology. Millstone Hill radar observations and analysis are supported by a NSF cooperative agreement with the Massachusetts Institute of Technology. We are grateful to various colleagues at Millstone Hill for the operation of the radar during the storm and for data processing, in particular to Phil Erickson, John Holt and Frank Lind. The authors also thank M. McCready and N. Aponte for their effort in processing of the data.

EISCAT is an international association supported by Finland, France, Germany, Japan, Norway, Sweden and the United Kingdom. The Sondrestrom Facility is operated by SRI International under cooperative agreement with the US National Science Foundation, ATM-9813556. The Kharkov incoherent scatter radar is supported by Ministry of Education of Ukraine. The Irkutsk incoherent scatter radar is supported by the state grant (NSh-272.2003.5) for Leading Scientific Schools of the Russian Federation and Russian Foundation for Basic Research (grant 03-05-64627). The Arecibo Observatory is operated by Cornell University with support from a cooperative agreement with the NSF. The Jicamarca Radio Observatory is operated by the Instituto Geofísico del Perú, with support from the NSF Cooperative Agreement ATM-9911209 through Cornell University. ACE data were supplied by the ACE Science Center website. The equatorial $D_{s t}$ data were obtained from the World Data Center C2 for Geomagnetism in Kyoto.

Topical Editor M. Lester thanks A. Aylward for his help in evaluating this paper.

\section{References}

Adeniyi, J. O.: Magnetic storm effect on the morphology of the equatorial F2-layer, J. Atmos. Terr. Phys., 48, 695-702, 1986.

Aponte N., Gonzalez, S. A., Kelley, M. C., Tepley, C. A., Pi, X., and Iijima, B.: Advection of the equatorial anomaly over Arecibo by small-storm related disturbance dynamo electric fields, Geophys. Res. Lett., 27, 2833-2836, 2000.

Buonsanto, M. J.: Ionospheric storms - a review, Space Science Rev., 88, 563-601, 1999.

Buonsanto, M., Salah, J., Miller, K., Oliver, W., Burnside, R., and Richards, P.: Observations of neutral circulation at midlatitudes during the equinox transition study, J. Geophys. Res., 94, 16987-16997, 1989.

Buonsanto, M. J. and Foster, J. C.: Effects of magnetospheric electric fields and neutral winds on the low-middle latitude ionosphere during the March 20-21, 1990 storm, J. Geophys. Res., 98, 19 133-19140, 1993.

Buonsanto, M. J., Gonzalez, S. A., Lu, G., Reinisch, B. W., and Thayer, J. P.: Coordinated incoherent scatter radar study of the January 1997 storm, J. Geophys. Res., 104, 24 625-24 637 , 1999 a.

Buonsanto, M. J., Gonzalez, S. A., Pi, X., Ruohoniemi, J. M., Sulzer, M. P., Swartz, W. E., Thayer, J. P., and Yuan, D. N.: Radar chain study of the May, 1995 storm, J. Atmos. Sol.-Terr. Phys., 61, 233-248, 1999b.

Buonsanto, M. J., and Witasse, O. G.: An updated climatology of thermospheric neutral winds and $\mathrm{F}$ region ion drifts above Millstone Hill, J. Geophys. Res., 104, 24 675-24 687, 1999.

Burnside, R. G., Tepley, C. A., and Sulzer, M. P.: World Day Observations at Arecibo: 1985 to 1989, J. Geophys. Res., 96, 36913710, 1991a.

Burnside, R. G., Tepley, C. A., Sulzer, M. P., Fuller-Rowell, T. J., Torr, D. G., and Roble, R. G.: The neutral thermosphere at Arecibo during geomagnetic storms, J. Geophys. Res., 96, 12891301, 1991b.

Crary, D. J. and Forbes, J. M.: The dynamic ionosphere over Arecibo: a theoretical investigation, J. Geophys. Res., 91, 249$258,1986$.

Danilov, A. D.: F2-region response to geomagnetic disturbances, J. Atmos. Sol.-Terr. Phys., 63, 441-449, 2001.

Fejer, B. G.: The equatorial ionospheric electric fields. A review, J. Atmos. Terr. Phys., 43, 377-386, 1981.

Fejer, B. G.: Low latitude storm time ionospheric electrodynamics, J. Atmos. Terr. Phys., 64, 1401-1408, 2002. 
Fejer, B. G., de Paula, E. R., Gonzalez, S. A., and Woodman, R. F.: Average vertical and zonal $\mathrm{F}$ region plasma drifts over Jicamarca, J. Geophys. Res., 96, 13 901-13 906, 1991.

Fejer, B. G. and Scherliess, L.: Time dependent response of equatorial ionospheric electric fields to magnetospheric disturbances, Geophys. Res. Lett., 22, 851-854, 1995.

Fejer, B. G., and Scherliess, L.: Mid- and low-latitude promptpenetration ionospheric zonal plasma drifts, Geophys. Res. Lett., 25, 3071-3074, 1998.

Field, P. R. and Rishbeth, H.: The response of the ionospheric F2layer to geomagnetic activity: an analysis of worldwide data, J. Atmos. Sol.-Terr. Phys., 59, 163-180, 1997.

Forbes, J. M., Palo, S. E., and Zhang, X.: Variability of the ionosphere, J. Atmos. Sol.-Terr. Phys., 62, 685-693, 2000.

Foster, J. C.: Storm time plasma transport at middle and high latitudes, J. Geophys. Res., 98, 1675-1689, 1993.

Fuller-Rowell, T. J., Codrescu, M. V., Moffett, R. J., and Quegan, S.: Response of the thermosphere and ionosphere to geomagnetic storms, J. Geophys. Res., 99, 3893-3914, 1994.

Fuller-Rowell, T. J., Codrescu, M. V., Rishbeth, H., Moffett, R., and Quegan, S.: On the seasonal response of the thermosphere and ionosphere to geomagnetic storms, J. Geophys. Res., 101, 2343-2354, 1996.

Fuller-Rowell, T. J., Codrescu, M. V., Roble, R. G., and Richmond, A. D.: How does the thermosphere and ionosphere react to a geomagnetic storm?, in: Magnetic storms, edited by Tsurutani, B. T., Gonzales, W. D., Kamide, Y., and Arballo, J. K., Geophysical Monograph 98, AGU, Washington D.C., 1997.

Haggstrom, I. and Collis, P. N.: Ion composition changes during F-region density depletions in the presence of electric fields at auroral latitudes, J. Atmos. Terr. Phys., 52, 519-529, 1990.

Hocke, K., and Schlegel, K.: A review of atmospheric gravity waves and travelling ionospheric disturbances: 1982-1995, Ann. Geophys., 14, 917-940, 1996,

SRef-ID: 1432-0576/ag/1996-14-917.

Hunsucker, R. D. and Hargreaves, J. K.: The high-latitude ionosphere and its effects on radio propagation, Cambridge University Press, 2003.

Idenden, D. W., Moffett, R. J., and Quegan, S.: Ionospheric structure produced during a rapid polar cap expansion, J. Geophys. Res., 102, 14581-14594, 1997.

Jenkins, B., Moffett, R. J., Davies, J. A., and Lester, M.: Nightside ion frictional heating: atomic and molecular ion temperature anisotropy and ion composition changes, J. Atmos. Sol.-Terr. Phys., 59, 1329-1341, 1997.

Kelley, M. C., Fejer, B. G., and Gonzales, C. A.: An explanation for anomalous ionospheric electric fields associated with a northward turning of the interplanetary magnetic field, Geophys. Res. Lett., 6, 301-304, 1979.

Kelley, M. C., Makela, J. J., Chau, J. L., and Nicolls, M. J.: Penetration of the solar wind electric field into the magnetosphere/ionosphere system, Geophys. Res. Lett., 30(4), 1158, doi:10.1029/2002GL016321, 2003.

Kohl, H., and King, J. W.: Atmospheric winds between 100 and $700 \mathrm{~km}$ and their effects on the ionosphere, J. Atmos. Terr. Phys., 29, 1045-1062, 1967.

Liu, H., Schlegel, K., and Ma, S.-Y.: Combined ESR and EISCAT observations of the dayside polar cap and auroral oval during the May 15, 1997 storm, Ann. Geophys., 18, 1067-1072, 2000, SRef-ID: 1432-0576/ag/2000-18-1067.

Lu, G., Pi, X., Richmond, A. D., and Roble, R. G.: Variations of total electron content during geomagnetic disturbances: a model/observation comparison, Geophys. Res. Lett., 25, 253256, 1998.

Mikhailov, A. V., Forster, M., and Skoblin, M. G.: Neutral gas composition changes and ExB vertical plasma drift contribution to the daytime equatorial F2-region storm effects, Ann. Geophys., 12, 226-231, 1994,

SRef-ID: 1432-0576/ag/1994-12-226.

Mikhailov, A., Skoblin, M. G. and Forster, M.: Daytime F2-layer positive storm effect at middle and lower latitudes, Ann. Geophys., 13, 532-540, 1995,

SRef-ID: 1432-0576/ag/1995-13-532.

Mikhailov, A. V. and Foster, J. C.: Daytime thermosphere above Millstone Hill during severe geomagnetic storms, J. Geophys. Res., 102, 17 275-17 282, 1997.

Mikhailov, A. V., and Schlegel, K.: Physical mechanism of strong negative storm effects in the daytime ionospheric F2 region observed with EISCAT, Ann. Geophys., 16, 602-608, 1998, SRef-ID: 1432-0576/ag/1998-16-602.

Moorcroft, D. R. and Schlegel, K.: Evidence for non-Maxwellian ion velocity distributions in the F-region, J. Atmos. Terr. Phys., 50, 455-465, 1988.

Nelson, G. J., and Cogger, L. L.: Dynamical behavior of the nighttime ionosphere at Arecibo, J. Atmos. Terr. Phys., 33, 17111726, 1971.

Pavlov, A. V., Buonsanto, M. J., Schlesier, A. C., and Richards, P. G.: Comparison of models and data at Millstone Hill during the 5-11 June 1991 storm, J. Atmos. Sol.-Terr. Phys., 61, 263-279, 1999.

Pi, X., Mannucci, A. J., Lindqwister, U. J., and Ho, C. M.: Monitoring of global ionospheric irregularities using the worldwide GPS network, Geophys. Res. Lett., 24, 2283-2286, 1997.

Prölss, G. W.: Ionospheric F-region storms, in: Handbook of atmospheric electrodynamics, v. 2, edited by Volland, H., CRC Press, Boca Raton, 195-248, 1995.

Richards, P. G., Torr, D. G., Buonsanto, M. J., and Sipler, D. P.: Ionospheric effects of the March 1990 magnetic storm: Comparison of theory and measurements, J. Geophys. Res., 99, 23359 $23365,1994$.

Rishbeth, H.: The effects of winds on the ionospheric F2-peak, J. Atmos. Terr. Phys., 29, 225-238, 1967.

Rishbeth, H. and Mendillo, M.: Patterns of F2-layer variability, J. Atmos. Sol.-Terr. Phys., 63, 1661-1680, 2001.

Roble, R. G.: The calculated and observed diurnal variation of the ionosphere over Millstone Hill on 23-24 March 1970, Planet. and Space Sci., 23, 1017-1033, 1975.

Roble, R. G., Dickinson, R. E., and Ridley, E. C.: Seasonal and solar cycle variations of the zonal mean circulation in the thermosphere, J. Geophys. Res., 82, 5493-5504, 1977.

Roble, R. G., Forbes, J. M. and Marcos, F. A.: Thermospheric dynamics during the March 22, 1979, magnetic storm, 1, Model simulations, J. Geophys. Res., 92, 6045-6068, 1987.

Sastri, J. H., Rao, H. N. R., and Ramesh, K. B.: Response of equatorial ionosphere to the transit of interplanetary magnetic cloud of 13-15 January, 1967, Transient disturbance in F region, Planet. Space Sci., 40, 519-534, 1992.

Scherliess, L., Fejer, B., Holt, J., Goncharenko, L., AmoryMazaudier, C., and Buonsanto M.: Radar studies of midlatitude ionospheric plasma drifts, J. Geophys. Res., 106, 1771-1784, 2001.

Schunk, R. W., Raitt, W. J., and Banks, P. M.: Effects of electric fields on the daytime high-latitude $\mathrm{E}$ and $\mathrm{F}$ regions, J. Geophys. Res., 80, 3121-3130, 1975. 
Sojka, J. J., David, M., and Schunk, R. W.: A mid-latitude space weather hazard driven directly by the magnetosphere, J. Atmos. Sol.-Terr. Phys., 64, 687-695, 2002.

Spiro, R. W., Harel, M., Wold, R. A., and Reiff, P. H.: Quantitative simulation of a magnetospheric substorm, 3. Plasmaspheric electric fields and evolution of the plasmasphere, J. Geophys. Res., 86, 2261-2272, 1981.

Szuszczewicz, E. P., Lester, M., Wilkinson, P., Blanchard, P., Abdu, M., Hanbaba, R., Igarashi, K., Pulinets, S., and Reddy, B. M.: A comparative study of global ionospheric responses to intense magnetic storm conditions, J. Geophys. Res., 103, 11 66511684,1998
Thayer, J. P., Heinselman, C. J., Tsunoda, R. T., van Eyken, A. P., Stromme, A., and McCready, M. A.: Observations of the high-latitude ionospheric response to the onset of the April 2002 storm, Eos Trans. AGU, 83(47), Fall Meet. Suppl., Abstract SA21B-0455, 2002.

Wand, R. H.: A model representation of the ionospheric electric field over Millstone Hill, J. Geophys. Res., 86, 5801-5808, 1981.

Zhou, Q. and Sulzer, M. P.: Incoherent Scatter Radar Observation of the F-Region Ionosphere at Arecibo During January 1993, J. Atmos. Solar-Terr. Phys., 59, 2213-2229, 1997. 